PNL-2763

UC-62

\title{
Summary Report of the Solar Reflective Materials Technology Workshop
}

\author{
M. A. Lind \\ L. E. Ault
}

October 1978

Prepared for the U.S. Department of Energy under Contract EY-76-C-06-1830

Pacific Northwest Laboratory Operated for the U.S. Department of Energy by 


\title{
NOTICE
}

This report was prepared as an account of work sponsored by the United States Government. Neither the United States nor the Department of Energy, nor any of their employees, nor any of their contractors, subcontractors, or their employees, makes any warranty, express or implied, or assumes any legal liability or responsibility for the accuracy, completeness or usefulness of any information, apparatus, product or process disclosed, or represents that its use would not infringe privately owned rights.

The views, opinions and conclusions contained in this report are those of the contractor and do not necessarily represent those of the United States Government or the United States Department of Energy.

\author{
PACIFIC NORTHWEST LABORATORY \\ operated by \\ BATTELLE \\ for the \\ UNITED STATES DEPARTMENT OF ENERGY \\ Under Contract EY-76-C-06-1830
}

\begin{tabular}{|c|c|c|}
\hline \multicolumn{3}{|c|}{$\begin{array}{l}\text { Printed in the United States of Am } \\
\text { Availabie from } \\
\text { National Technical Information Se } \\
\text { United States Department of Comi } \\
\text { S285 Port Royal Road } \\
\text { Springtield, Virginia } 22151\end{array}$} \\
\hline Price: & Printed Copy 5 & _ Microfic \\
\hline & 'Pages & $\begin{array}{l}\text { NTIS } \\
\text { Selling Price }\end{array}$ \\
\hline & $001-025$ & 5400 \\
\hline & $025-050$ & $\$ 4.50$ \\
\hline & $051-075$ & $\$ 5.25$ \\
\hline & $075-100$ & 56.00 \\
\hline & $101-125$ & $\$ 6.50$ \\
\hline & 126.750 & 57.25 \\
\hline & $151-175$ & $\$ 8.00$ \\
\hline & $175-200$ & 59.00 \\
\hline & $201-225$ & $\$ 9.25$ \\
\hline & $225-250$ & $\$ 9.50$ \\
\hline & $251-275$ & 510.75 \\
\hline & $276-300$ & $\$ 11.00$ \\
\hline
\end{tabular}


PNL-2763

UC-62

\title{
33679000492860
}

\author{
SUMMARY REPORT OF THE SOLAR \\ REFLECTIVE MATERIALS \\ TECHNOLOGY WORKSHOP
}

M. A. Lind
L. E. Ault

October 1978

Prepared for the U.S. Department of Energy under Contract EY-76-C-06-1830

Pacific Northwest Laboratory

Richland, Washington 99352 
1

.

$\mathbf{n}$ 


\section{FOREWORD}

This document provides an overview of the Solar Reflective Materials Workshop which was held in Denver, Colorado on March 28-30, 1978. No attempt has been made to reproduce the complete proceedings of the conference; but rather, the authors of this summary have compiled the highlights of the presented papers and workshop sessions. An executive summary is included in the first part of the document which outlines the basic purpose and organization of the conference and summarizes the presentations and the conclusions of the participants.

Many people contributed to the organization and execution of the workshop. Special thanks are due to Mr. H. L. Hampton (PNL), and Dr. P. L. Call (SERI), for their contributions to the basic format of the workshop and the content of the questionnaire.

One of the underlying purposes of the workshop was to provide background information for recommending to DOE a general R\&D plan for solar reflective materials. At the conclusion of the workshop, an outline of such a plan was compiled by representatives of several leading DOE laboratories for consideration as a National Reflector Materials R\&D plan. A copy of this outline, which is currently being incorporated into the National Solar Materials Plan by SERI, is included in the document.

This outline is the result of many successive iterations. Significant contributions to the plan were made by: M. A. Adams (JPL), B. L. Butler (SERI), P. L. Call (SERI), W. F. Carroll (JPL), M. A. Lind (PNL), K. Masterson (SERI), and R. B. Pettit (SLA). The plan was compiled with the support and encouragement of M. Gutste in and L. Melamed of the DOE Advanced Solar Thermal Technology R\&D Branch. An outline of the plan was first presented at the Advanced Solar Thermal Technology Semi-Annual Review meeting held in Golden, Colorado on May 9-11, 1978. 


\section{CONTENTS}

FOREWORD. • • • • • • • • • • • • • • • • • • • • •

EXECUTIVE SUMMARY $•$ •

RECOMMENDATIONS: A PLAN FOR THE NATIONAL REFLECTOR

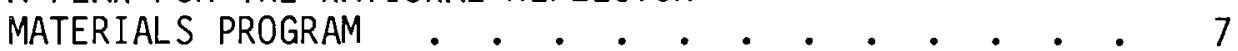

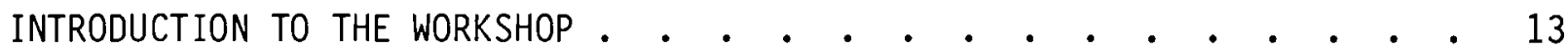

WORKSHOP OBJECTIVES • • • • • • • • • • • • • • • • • • • • 15

INVITED AND CONTRIBUTED PAPERS

INTRODUCTION • • • • • • • • • • • • • • • • • • • • 17

LIST OF SPEAKERS AND INDEX TO PAPERS. • • • • • • • • • • 18

REVIEW OF PAPERS • • • • • • • • • • • • • • • • •

WORKING GROUP SESSIONS • • • • • • • • • • • • • • • • •

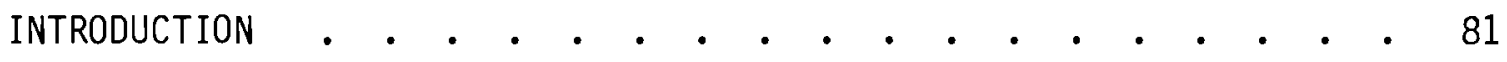

SUMMARY OF RESPONSES TO MATRIX QUESTIONNAIRE • • • • • • • • • • 82

SUMMARY OF RESPONSES TO GENERAL PHILOSOPHY QUESTIONS • • • • $\quad 84$

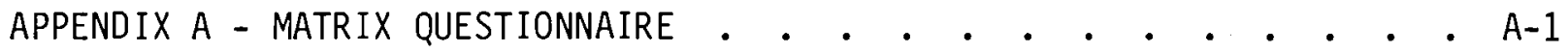

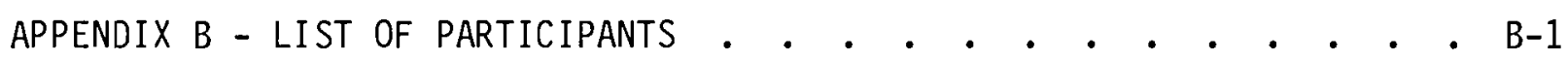




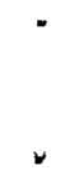




\section{EXECUTIVE SUMMARY}

The Solar Reflective Materials Technology Workshop sponsored by the Department of Energy and organized by the Pacific Northwest Laboratory and the Solar Energy Research Institute was held on March 28-30, 1978 in Denver, Colorado. The two and one-half day seminar/workshop was attended by over 95 people representing some 60 private companies and government laboratories.

The purpose of the workshop was to assess the "state-of-the-art" of solar reflector materials technology, define current mirror design requirements, and make recommendations to DOE for future research and development efforts.

The first day and a half of the conference was devoted to the presentation of invited and contributed papers. In the following half day the workshop participants were divided into small parallel working groups and asked to answer a prepared questionnaire designed to review specific materials properties and stimulate discussion in topics of current concern in the solar reflector materials community.

On the third morning a general session was reconvened to review the inputs of the previous two days and solicit further comments and discussion from the participants.

Immediately following the workshop, a special committee was convened to formulate specific recommendations to DOE which reflect the output of the workshop. The committee was comprised of representatives from SERI, PNL, JPL and SLA. The final recommendations were in the form of a general program plan outline for solar reflector materials. It was also recommended that this plan be coordinated by SERI in cooperation with a11 the various DOE branches with interests in solar concentrator technology.

The reflector materials are defined for the purpose of this workshop as including all the materials which make up the reflector structure including the actual reflecting surface, the protective coatings, and the support substrate. The reflective surface includes metals, metallic films, metallic alloys, and dielectric or ceramic stacks. The protective coatings, which can 
be applied to both the front and back of the reflective surface, include such materials as polymer paints and films as well as inorganic coatings such as $\mathrm{SiO}, \mathrm{MgF}_{2}$ and thin glass. Mirror support structures which have been considered include polymer foams, cellular glass, aluminum honeycomb, wood and paper products, and fiberglass and epoxy composites.

The authors of the invited papers were asked to emphasize one or more of four basic areas. These topics included: the requirements and properties for reflector materials, the testing procedures used to evaluate the materials, the results of environmental tests performed on some of the materials, and the actual field experience of solar concentrator structures. Acknowledging that the most severe applications for reflector materials result from high concentration ratio or central receiver concepts, the majority of the speakers addressed specific problems dealing with these concepts.

The preferred specifications for solar reflectors can be easily defined but are difficult to achieve. The reflector should be perfectly specular and should have a solar reflectance as close to unity as possible. The substrate should be capable of supporting the reflective surface and maintaining a given geometrical figure under all external environmental stresses. The reflector should not degrade in performance over its estimated 20-40 year 1 ifetime. And finally, the cost per unit area of the entire reflector unit should be minimized. As is the case in all areas of materials technology, all these attributes cannot be achieved simultaneously and the end product is a cost/ performance compromise, hopefully an optimal one.

The current state of knowledge of the intrinsic properties of the reflector materials is not as easily defined. A large number of materials are currently being used or have been proposed for use in solar reflector structures. Unfortunately, while a considerable effort has been expended on materials characterization, the majority of the data which relates to the mechanical and especially the optical properties of the materials and their long term environmental stability is either incomplete, inconsistent or lacking entirely. 
The reason for this lack of a good data base can be attributed to three main causes. First, the problem of materials aging, durability and lifetime prediction is a difficult one. No easy answers have been found and there is no reason to expect answers in the immediate future without additional sound basic research. Second, the current programs addressing materials problems are too immature to have yielded significant results on all but a few of the material systems. Finally, the measurement technology and techniques, especially those germain to the optical properties of the materials such as specularity and figure, are not well defined or we 11 understood by the majority of the community.

In the presented papers, the speakers discussed topics ranging from theoretical design concepts and new material ideas to the hard core field experience of mirror modules. Mirror design parameters and optimization considerations for materials and structures were discussed. Exposure testing methodology for materials (what to measure, how to measure it and what instrumentation is required) was presented. The results of actual materials tests were the subject of several papers. Factors that were considered included optical and mechanical properties, weathering, laboratory and field performance, dust buildup, cleaning and the effects of wind and hail on the materials and structures. Speakers keyed on performance of the protective surfaces, the mirror surface itself and the supportive substrate. Other papers ranged from what is known about glass as a protective material, to what might be done to aluminum to increase its solar reflectance while maintaining its desirable weathering properties. An extended abstract of each of the papers as edited from the complete transcripts of the meeting is presented in Section $V$.

Perhaps the most significant direct output from the seminar/workshop was the comments made by the participants during the workshop sessions both in response to the questionnaire and on their own volition. A summary of the questions and responses is presented in Section VI of this report.

The consensus was that the standardization of terminology and test procedures is necessary. The stabilization of terminology and measurement 
techniques for reflector characterization is also highly desirable. The need is especially acute for optical properties definitions of specularity and slope error. A variety of techniques are currently being used to measure these parameters which are not easily compared.

Whereas most of the available standards for optical properties are not directly applicable to solar needs, the ASTM standards are deemed adequate for testing mechanical properties of materials and structures. However, the participants concluded that impact testing requires a better basic understanding. The main questions centered around whether or not ice ball and steel ball tests simulate the effects of hail. There was also doubt cast on the significance of hardness and toughness tests and their relation to abrasion and impact resistance. Standardized tests for thermal distortion and rigidity of reflector structures also need to be developed.

In addition, the need for standard test methods for assessing the durability and weatherability of materials was emphasized. Information which is needed to correlate the results of accelerated testing programs with real time environmental exposure is lacking. Caution should be exercised to see that any standards or specifications which are developed take into account regional differences.

The areas where a stronger and more complete data base need to be established include reflectance, transmittance and specularity of optical materials. The need is also acute for materials durability, weatherability, life expectancy, and economics. The fundamental limitations of specific material types and areas of long range potential for improvement of performance should be established.

Dust and dirt interactions with mirrors and their effect on performance is being looked at. More work is necessary, especially relating to cleaning and inhibiting dust adhesion.

The workshop participants were also asked to prioritize the areas of a reflector materials program that should be addressed. Their response indicated that weatherability and durability measurements, improved field measurements, cleaning techniques and standardization rate high on the 1 ist. 
Rated at the bottom of the list were process and fabrication techniques, refinement and development, as well as more laboratory measurements.

The participants concluded that a government coordinated R\&D program is necessary. There is probably already too much duplication of effort. Special emphasis should be placed on better and faster communications and technology transfer. Government programs should maintain relevance to the needs of the solar community and concentrate on long range (greater than ten years) problems. The manufacturers at the conference also expressed their concern with better government incentives for commercialization, protection of proprietary interests of the small business, and the tendency of the government to specify the best rather than typical performance in their reports and requirements. 
. 


\section{RECOMMENDATIONS: A PLAN FOR THE NATIONAL}

REFLECTOR MATERIALS PROGRAM

As a direct consequence of the Solar Reflector Materials Technology Workshop, an executive committee composed of representatives from SERI, PNL, JPL and SLA was convened to draft the summary recommendations of the workshop in the form of an outline for a National Reflector Materials Program Plan. The plan reflects the majority viewpoint of the workshop participants and the executive committee.

The plan outline is the product of multiple iterations between members of the committee. A summary of the entire plan was presented at the Advanced Solar Thermal Technology Semi annual Review Meeting held in Golden, Colorado on May 9, 1978. It was further recommended that this $\mathrm{plan}$ be adopted and coordinated by SERI as part of the National Solar Materials R\&D plan. 


\section{OUTLINE OF PRELIMINARY PLAN FOR THE NATIONAL REFLECTOR MATERIALS PROGRAM June 3, 1978}

I. Management

1. Program planning

a. Cost/risk/benefit analysis

b. Establish priorities and program level

c. Update plan periodically

2. Coordination

a. Initiate and direct program

b. Interaction between all reflector technology areas (BES, photovoltaics, heating and cooling, solar thermal, projects, etc.)

c. Coordination within the program

3. Data Base

a. Establish and maintain data base (theoretical, experimental, and engineering)

b. Cross reference with other existing data bases (SEIDB, CINDAS, etc.)

4. Information Dissemination

a. Workshops and seminars

b. Central distribution alternatives

c. Reports and monographs

II. Materials R\&D

1. Reflector Materials

a. Metallic alloys

1) amorphous $\mathrm{Al}$

2) $\mathrm{Ag} / \mathrm{Al}$ stacks

3) organometallic chelates 
4) Ag alloys

5) high temperature secondary concentrator materials

6) theory

7) other concepts

b. Other materials

1) dielectric stacks

2) ceramics

2. Reflector Substrate Materials

a. Glass

1) ultra-thin glass $(<0.010$ in.)

2) increased smoothness, reduced internal scattering, glass forming

3) low absorptance formulations

b. Polymers

1) films

2) sheets

3. Protective Coatings (front and/or back)

a. Polymers (paints, films, etc.)

b. Inorganics (SiO, $\mathrm{MgF}_{2}$, thin glass, etc.)

c. Metallics (copper backplating, etc.)

d. Alternate protection concepts (sacrificial, scavenger, galvanic, etc.)

4. Mirror Support Materials and Structures

a. Polymers (foams, etc.)

b. Ceramics (cellular glass, etc.)

c. Metals (A1, honeycomb, etc.)

d. Wood and paper products

e. Composites (fiberglass, epoxy, etc.)

f. Other

5. Mirror Attachment Technology

a. Adhesive bonding

1) organic

2) inorganic 

b. Mechanical
c. Glass frit bonding
d. Electrostatic bonding
e. Other

6. Mirror Refurbishment/Replacement Technology
a. Factory refurbishment
b. Field repair
c. Recycling or reusing units
d. Other concepts

III. Large Scale Manufacturing Technology (development activity for applying advanced technology of Section II to production processes)

1. Reflector Materials

2. Substrate Materials

3. Protective Coatings

4. Mirror Support

5. Mirror Attachment Technology

6. Mirror Refurbishment/Replacement Technology

IV. Measurement and Standards

1. Intrinsic Mirror Quality
a. Definition
b. Standards
c. Measurement Procedures and Techniques

2. Configurational Accuracy
a. Definition
b. Standards
c. Measurement Procedures and Techniques

1) laser ray trace

2) optical imaging

3) fourier transform

3. Design and Engineering Data

4. Instrument Development and Commercialization
a. Specular Reflectance 

b. Configurational Accuracy
c. Flux Distribution at Receiver
d. Quality Control
e. Field Portable

V. Long Term Performance

1. Performance Prediction Modeling

a. Degradation Mechanisms

b. Models

2. Test Development (real time and accelerated)

a. Exposure (development of test methods)

b. Diagnostics (what to measure, how to measure it, instrumentation development)

c. Correlations (between testing and real world performance)

3. Degradation Mechan isms

a. Dust-Surface Interaction

1) fluid mechanics of deposition

2) chemistry and physics of adhesion

b. Chemical Corrosion and Erosion

c. Ultraviolet, Moisture, Temperature, etc.

4. Degradation Control

a. Continuous Dust Control

1) electrostatic

2) ultrasonic

3) streamlining

b. Washing with Detergents

c. Coatings (Permanent and Replaceable)

d. UV Stabilization, Edge Protection

5. Economic Strategy
a. Performance
b. Reliability
c. Life cycle costs

VI. Other (e.g., Fresnel lenses, secondary concentrator mirrors, etc.) 


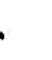

. 


\section{INTRODUCTION TO THE WORKSHOP}

The Solar Reflective Materials Technology Workshop sponsored by The Department of Energy and organized by Pacific Northwest Laboratory and The Solar Energy Research Institute was held on March 28-30, 1978 in Denver, Colorado. The workshop was attended by approximately 95 individuals representing 60 private companies and government laboratories.

The two and one-half day conference was organized into the three successive sessions listed below:

1. Invited and contributed papers on topics covering the following areas.

- Intrinsic properties of mirror materials and structures

- Exposure test results and environmental effects of reflectors

- Measurement and testing methodology

- Innovative materials and structures

2. Parallel working group discussions each covering:

- Materials "state of the art" questionnaire

- General philosophy questions regarding specific problems of the reflector community and expected DOE participation and direction

- Unsolicited comments from the participants

3. A general open session covering:

- A summary of the previous day's working group discussions

- Comments and exchanges between DOE representatives and workshop attendees

The stated workshop objectives are listed in Section IV of this report. A review of the invited and contributed papers which were presented in Session $I$ is given in Section $V$. The review is in the form of extended abstracts of each of the papers. A review of the working group session, as well as a copy of the questionnaire, is presented in Section VI and a list of the participants in this first reflector materials oriented workshop is given in Appendix B. 
$\cdot$
$\sim$ 


\section{WORKSHOP OBJECTIVES}

The workshop was designed to provide a platform for greater interaction and information exchange between users, manufacturers and researchers with interests in solar reflectors.

The objectives were:

1. To identify the current state of the art of the solar reflector technology with emphasis on the following:
a. materials' properties
b. material availability
c. reflector surface construction
d. user experience
e. characterization techniques

Particular attention was to be placed on the present ability to meet design requirements.

2. To define mirror design requirements with respect to each of the following:
a. reflectance
b. specularity
C. fabrication constraints
d. maintenance
e. life expectancy
f. economics

3. To develop recommendations for DOE program goals and areas for future research and development support. 



\section{INVITED AND CONTRIBUTED PAPERS}

INTRODUCTION

This section of the report contains an abbreviated review of the invited and contributed papers presented during the first day and one-half of the workshop. Each paper which was presented has been summarized from the complete transcripts of the meeting by the authors of this report. It was the authors' intent to preserve the most germain material in a concise and readable format.

Readers desiring more complete information should contact the authors directly. Authors addresses and telephone numbers can be found in Appendix $B$ of this report. 


\section{LIST OF SPEAKERS AND INDEX TO PAPERS}

Introductory Remarks

- M. Lind, Pacific Northwest Laboratory . . . . . . . . . . . . . . . . 13

Reflector Technology Requirement

- W. Carroll, JPL . . . . . . . . . . . . . . . . . . 21

SERI and Solar Energy Materials R \& D

- Pat Call, SERI . . . . . . . . . . . . . . . . . 23

Exposure Test Results for Reflective Materials

- R. A. Rausch, Honeywel1 . . . . . . . . . . . . . . . . . 24

Results from Experiments with Glass Mirrors and Assemblies for Heliostats

- J. Thornton, Martin Marietta Corporation . . . . . . . . . . . . 29

Application for Polystyrene Foams for Heliostat Mirror Modules

- J. J. Dietrich, McDonnell Douglas Astronautics Company. . . . . . . 33

Development of Membrane Reflectors for Solar Central Receiver Heliostats

- M. J. Berry, Boeing . . . . . . . . . . . . . . . . . . 37

Heliostat Glass Mirror Module and Low Iron Float Glass Evaluation

- C. L. Mavis, Sandia Laboratories, Livermore . . . . . . . . . . 39

Survey of Solar Reflector Material Properties

- R. B. Pettit, Sandia Laboratories, Albuquerque . . . . . . . . . .

Testing of Solar Reflective Materials - Experience vs. Requirements

- J. E. Gilligan, IIT Research Institute . . . . . . . . . . . . .

The Simulation of Solar-Thermal Energy Conversion Systems

- G. L. Schrenk, University of Pennsylvania . . . . . . . . . . . . .

The Effect of Environment on Glass Surfaces

- P. B. Adams, Corning Glass Works . . . . . . . . . . . . . . . .

Dust Buildup and Cleaning of Solar Reflectors

- R. S. Berg, Sandia Laboratories, Albuquerque . . . . . . . . . .

The Effects of Glass Waviness on Heliostat Mirror Performance

- W. R. Delameter, Sandia Laboratories, Livermore . . . . . . . . . .

Augmented Solar Energy Collection Using Different Types of Planar Reflective Surfaces; Theoretical Calculations and Experimental Results

- D. P. Grimmer, Los Alamos Scientific Laboratory . . . . . . . . . . . 63

Field Evaluation of Solar Mirror Survivability

- R. M. Bethea, Texas Tech University. . . . . . . . . . . . . 
Hail Impact Tests of Solar Mirrors

- M. L. Smith, Texas Tech University . . . . . . . . . . . . . . . . . 69

Solar Reflective Materials at the Solar Pump

- F. Munoz, National University of Mexico... . . . . . . . . . . . 71

An Integrated Materials Development Approach to a Reflective Structural System

- W. D. Mitchell, Solaramics, Inc. ................ . 73

Enhanced Reflectivity Aluminum

- D. M. Trotter, Jr., Cornell University . . . . . . . . . . . . . . . 75

Sunlight Concentration for Silicon Rod Solar Cells

- G. L. Ball III, Monsanto Research Corporation . . . . . . . . . . 77

The Development of Standards for Spectral/Specular Reflectance

- J. Richmond, Bureau of Standards ................ . 79 



\section{"Reflector Technology Requirements" \\ W. Carroll, Jet Propulsion Laboratory}

One of the questions that this workshop should address is "do we need technology in reflector materials? If so, what should it be? What direction should it go? What should the scope be and how should it be implemented?" More specifically, "what do we need in the way of reflector technology? When do we need it and how bad do we need it? What's the payoff? What's currently available? Where are we going? What is the schedule and cost in terms of development?"

The main driver for reflectors is the cost per kilowatt electric. Figure 1 shows schematically how the cost of a reflector in a system per kilowatt electric is a function of the reflector quality. The curve shown is more likely a family of curves. It is obtained by summing the curve for the installed cost $/ \mathrm{m}^{2}$ and the curve for the reflector area needed to produce a kilowatt of electric. The installed cost $/ \mathrm{m}^{2}$ includes the cost of the actual reflector material, assembly, cleaning and maintenance, installation, tracking and operation. The reflector area needed depends on the mirror performance, the system design and operational considerations.

For the curve in Figure 1 , it has not yet been determined where the optimum value lies. In fact, we cannot even assign numerical values to the axes or give a value to the breadth of the curve for a given system. In determining these parameters, "a thorough systems analysis is required; off-the-cuff development calculations won't do the job." The interactions are all very important. Single point analysis can be misleading and dangerous. The total operating strategy should be considered, not just some nominal or best sunny day design point.

The key performance parameters for solar reflectors include:

- reflectance and specularity (material properties)

- slope error, soil accumulation and aging (material dependent)

- pointing-error and deflection-error (system design dependent)

Parametric studies using all these parameters should be performed in order to determine where the technology needs to go from where it is at the present. 


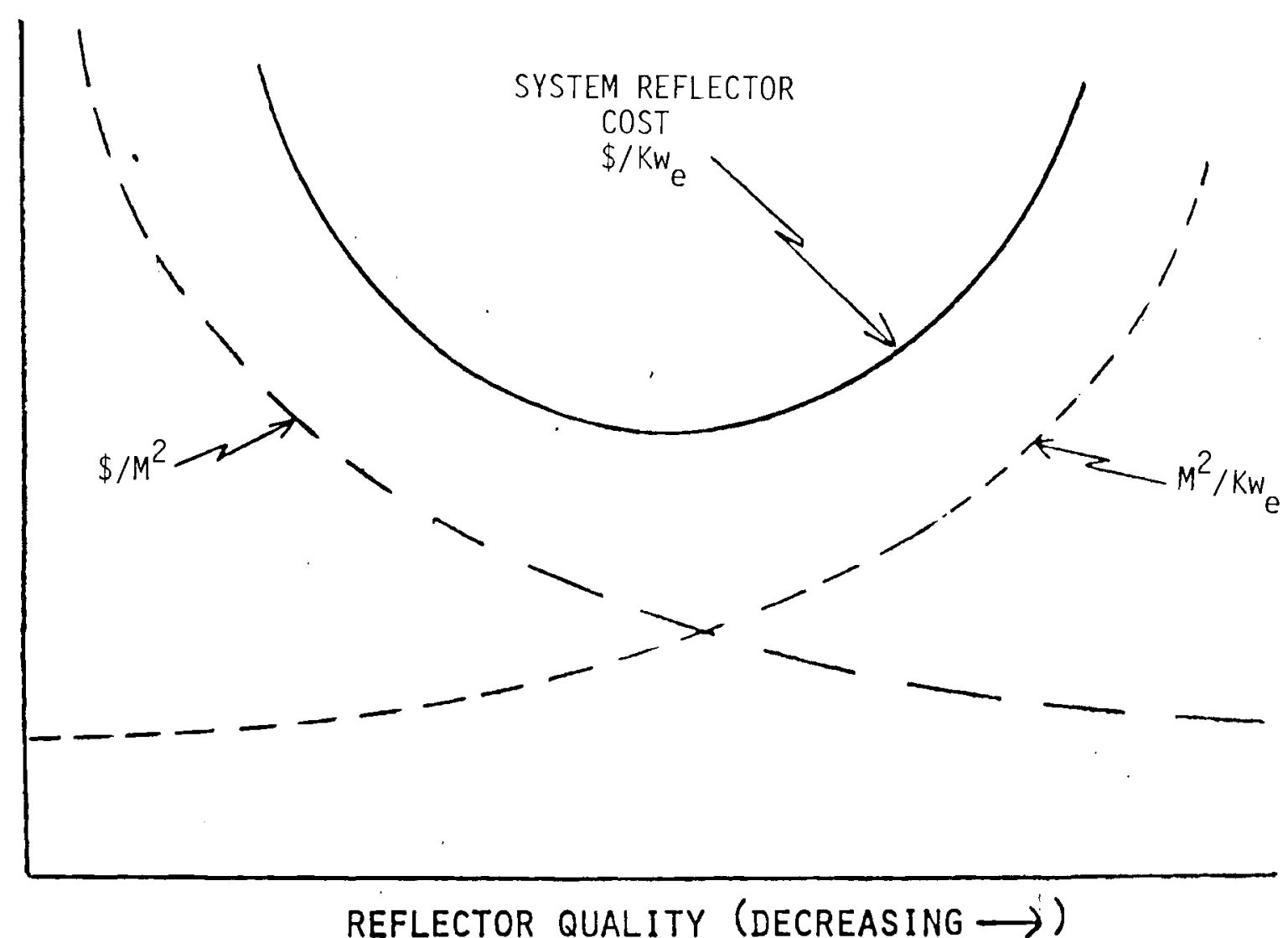

FIGURE 1. System Reflector Cost/Kilowatt Electric as a Function of Reflector Quality 
"SERI Materials R\&D"

P. Ca11, SERI

A brief overview of the organization of the Materials Branch at SERI and how it fits into the SERI structure was presented. The chief objective of this branch of SERI is to "develop materials options and to minimize life cycle costs and achieve optimum material utilization in solar energy conversion systems." The overall program will be "to identify and catalog existing and projected materials limitations imposed on solar systems and to try to determine effects of materials performance or reliability and lifetime of those systems." The disciplines that SERI intends to pursue to achieve these objectives include metals, polymers, inorganic-nonmetallics, surfaces and interfaces, and composites. The results of research in these areas will go toward compiling an accessible materials data bank and developing standards for materials and systems.

Also presented was a proposal that SERI has developed for the management of DOE programmatic funds. If an R\&D program to investigate generic reflector questions and issues and long-term research is determined to be important, then "SERI stands ready to assume the management responsibility for such a program in support of the Advanced Thermal Power Technology Branch."

When a program plan has been accepted by DOE, it will then be SERI's responsibility to select, fund, monitor and review the contractors to meet the objectives of the program as well as to determine the testing requirements of the program to insure that the objectives of the program are met. The SERI program manager will have sole authority for definition, funding, level of effort and, if necessary, redirection of the individual contracts. SERI will then report to the DOE program manager on a regular basis.

Comments on the proposed program management are solicited. 
"Exposure Test Results for Reflective Materials"

R. A. Rausch and B. P. Gupta ${ }^{(a)}$, Honeywe 11 Energy Resources Center

With up to 2-1/3 years of real time exposure, exposure tests have been conducted on a variety of candidate reflective materials for applications requiring concentration of solar energy since 1972. Materials tested include first surface aluminized fiberglass (General Dynamics), second surface aluminized acrylic ( $3 M$ and RAM products), second surface aluminized and silvered teflon (Sheldahl), second surface aluminized and silvered glass (Carolina Glass), and first surface anodized aluminum (Alcoa Alzak).

Three different simultaneous exposure tests (EEK, EMMA and EMMAQUA) were performed at Desert Sunshine's test site in Arizona. The test descriptions are shown in Table 1. The EMMA and EMMAQUA tests are accelerated exposure tests of approximately eight suns.

The results of the tests are shown in Table 2 and summarized below. The reflectance is for approximately a three degree acceptance cone and it is solar weighted. The measurement accuracy is estimated to be $\pm 1 \%$.

Although the data presented appears to be somewhat scattered and inconsistent possibly due to the cleaning techniques used, general trends can be inferred. The test results are summarized below.

1. Aluminized fiberglass - All of the samples failed the EEK test and showed significant loss of reflectivity under the accelerated tests. Generally, the surface becomes pitted and small gold/green spots appear. These spots expand to cover the entire surface, causing failure.

2. Aluminized acrylic - Aluminized acrylic has shown no degradation under EEK test conditions. Accelerated exposure has increased the reflectivity loss to 6 and 19 percent, respectively, for EMMA and EMMAQUA tests.

\section{(a) Present Ty SERI}




\section{TABLE 1. Exposure Test Descriptions}

- EEK

1. Equatorial Mount

2. 24-Hr Synchronous Drive

3. No Sample Shielding at Night of Overcast Periods

4. One Sun Exposure

- EMMA

1. Equatorial Mount

2. Sun Tracking

3. Protection of Samples When Sun Not Shining

4. Air Cooled

5. Eight-Sun Accelerated Exposure

- EMMAQUA

1. Same as EMMA Except Disti1led Water Spray

2. Occurs for Eight Minutes Per Sunny Hour 
TABLE 2. Superior Reflective Materials and Results of Exposure Tests

\begin{tabular}{|c|c|c|c|c|}
\hline $\begin{array}{c}\text { Test } \\
\text { Condition }\end{array}$ & Material & $\begin{array}{l}\text { Exposure } \\
\text { Per iod } \\
\text { (Weeks) } \\
\end{array}$ & $\begin{array}{c}\text { Original } \\
\text { Reflectivity } \\
(\rho) \\
\end{array}$ & $\begin{array}{c}\text { Ref lectivity Change } \\
\text { After Exposure } \\
(\Delta \rho)\end{array}$ \\
\hline \multirow[t]{3}{*}{ EEK } & Silvered Teflon & 135 & 0.86 & +0.01 \\
\hline & Aluminized Acrylic & 139 & 0.86 & 0.00 \\
\hline & Aluminized Teflon & 135 & 0.78 & +0.02 \\
\hline \multirow[t]{4}{*}{ EMMA } & Silvered Teflon & 129 & 0.85 & -0.07 \\
\hline & Aluminized Acrylic & 139 & 0.88 & -0.06 \\
\hline & Aluminized Teflon & 129 & 0.78 & +0.02 \\
\hline & Anodized Aluminum & 140 & 0.82 & -0.03 \\
\hline \multirow[t]{4}{*}{ EMMAQUA } & Silvered Teflon & 129 & 0.87 & -0.10 \\
\hline & Aluminized Acrylic & 129 & 0.85 & -0.19 \\
\hline & Aluminized Teflon & 129 & 0.79 & +0.01 \\
\hline & Anodized Aluminum & 129 & 0.82 & -0.10 \\
\hline
\end{tabular}


3. Aluminized and silvered teflon - The aluminized teflon samples show no significant loss of reflectivity under either normal or accelerated exposure conditions. Test results suggest that reflectivity actually increased as much as five percent during the EEK exposure tests. The silvered teflon material did not degrade under the EEK test, but under the accelerated test it degraded at a faster rate than the aluminized teflon. Green/gold spots have appeared on the accelerated test samples and small scratches appeared on half of the sample lot.

4. Aluminized and silvered glass - Little if any degradation occurred on the aluminized glass and the silvered glass samples except under the EMMAQUA test. A11 samples still have a good appearance.

5. Anodized aluminum - The anodized aluminum samples show little loss of reflectivity after 1-1/2 years of EEK exposure and up to ten percent loss under the accelerated tests. Samples are generally in good visual condition except that white spots exist on the EMMAQUA samples. These spots may be caused by the water spray as they exist on several other material samples subjected to the EMMAQUA test.

A linear average reflectivity was calculated for each of the test periods and a final average reflectivity value determined. Based on this performance parameter, the aluminized acrylic and the silvered teflon are the superior reflective materials. 


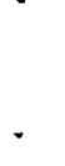


"Results from Experiments with Glass Mirrors and Assemblies for Heliostats"

J. Thornton and J. Vega, Martin Marietta Corporation

Martin Marietta has experimented extensively with glass mirrors and mirror assemblies for use on heliostats in central receiver applications since 1974. Four experimental heliostats have been fabricated and installed in the Martin Marietta Solar Test Facility. Three were twenty-five facet heliostats with high-performance mirrors with variable focus capability and one was a nine facet "commercial concept" heliostat employing fixed focus mirror assemblies. Except for the number of facets and the method of focusing, most features were common between the two configurations. The most significant features include a reflective surface area of $400 \mathrm{ft}^{2}$, an azimuth-elevation drive system, face-down storage of the mirrors for environmental protection, and a closed-loop fine tracking system which employs a tower-mounted sensor.

The test facility simulates the key features in the Martin Marietta baseline design for a commercial solar thermal plant. Their features are: a north field, approximately $295 \mathrm{ft}$ tower height, and heliostat to receiver slant ranges between 889 and $1659 \mathrm{ft}$.

The receiver area is instrumented with a water calorimeter and a radiometer boom. The calorimeter is essentially a 24 foot square flat plate collector painted with 3M Black Velvet. The radiometer boom has 13 separate radiometers placed at two foot intervals. The instruments are used to verify modeling of heliostat designs and checking calculated performance specifications. They are useful for measuring image flux distributions, and measuring real tracking errors of the heliostat. Typical image flux plots obtained from the radiometer boom are shown in Figure 1. The calculated uncertainity for the instruments is $\pm 4.5 \%$ for the radiometer. The instruments generally agree to within a few percent.

One can define a mirror performance factor (MPF) which is the incident energy received at the target divided by the energy incident at the surface of the mirror. Measured MPF's for the four mirrors at the test facility ranged 

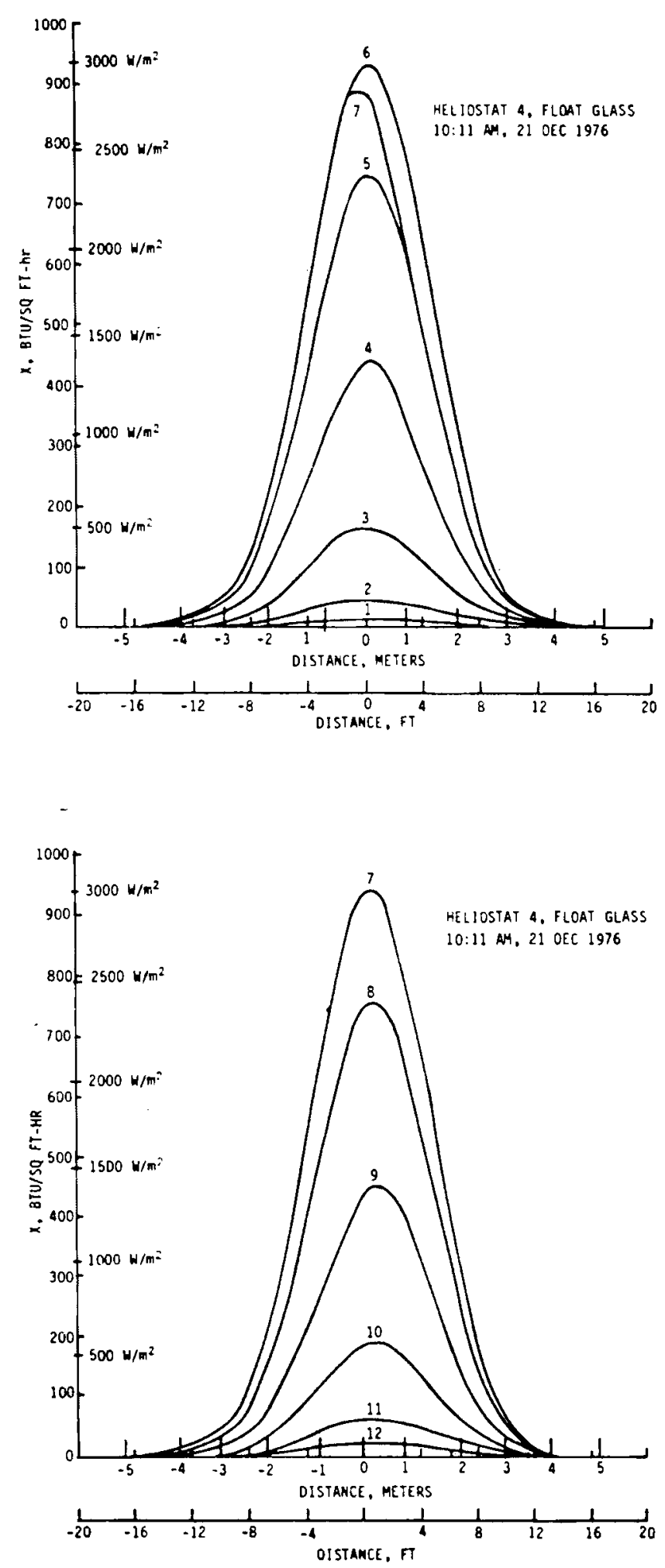

FIGURE 1. Typical Image Flux Plots From the Radiometer Boom Instrument 
from 74 to $83 \%$ depending on the type of glass used and the slant range. Loss due to aerosol scattering and atmospheric absorption at the 1200 foot slant range were about 3\%. On smoggy days the MPF dropped 11\%. The MPF was also reduced over $5 \%$ during one period where the mirrors remained uncleaned for 38 days.

Hailstone impact tests were performed on two samples, one with a foam core and one with a honeycomb core. The conclusion drawn from these tests is that hail is not a "big significant design factor, and the mirror can pretty much survive in any orientation you want."

Some glass strength testing was also done. The results of these tests on clear and mirrored float glass with scored and cracked edges indicate that the mean tensile stress at which $3 \mathrm{~mm}$ thick low iron float glass can be expected to break is approximately $7331 \mathrm{psi}$. This agrees very closely with theory. 


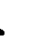

. 
"Application of Polystyrene Foams for Heliostat Mirror Modules"

J. J. Dietrich, McDonnell Douglas

Heliostat mirror modules must have a highly accurate slope, good performance, long life and be low in cost to insure a cost effective heliostat for the central receiver concept. Foam sandwich mirror modules using polystyrene foams meet all of these requirements.

Five second surface mirror configurations were considered: 1aminated glass on hat section stringers, thin glass ( 0.125 inches) on hat section stringers, glass-styrofoam-steel sandwich, thin glass bonded to steel backing or hat section stringers, and thin glass bonded to a corrigated stiffener steel backing. Comparisons of these mirror configurations are shown in Table 1.

The configuration under consideration for this study is that of the foam core sandwich. The mirror material, 1/8 inch second surface glass mirror, has a high specular reflectivity, a high modulus, a long life, is easily cleaned and is low in cost. The backface sheet made of 26 gage ( 0.0217 inches) galvanized sheet steel has a high modulus, a coefficient of thermal expansion close to glass, a long life with low maintenance. It is low in cost and is available in large quantities. The styrofoam core is low in cost, has a shear modulus $2800-1000$ psi, is 2 inch minimum thickness, is flat, is available in large quantities and has a long life. The mirror module verification tests (test type, description and results) are shown in Table 2. Proper materials and assembly methods show no degradation between the mirror and the mirror module and performance.

Foam sandwich mirror modules have the required characteristics of accurate slope, good performance, long life and low costs. Styrofoam is the most cost-effective core material available today for mirror modules. All tests and analyses completed to date show styrofoam to be completely satisfactory for mirror module applications. 
TABLE 1. Comparison of Second Surface Mirror Configurations

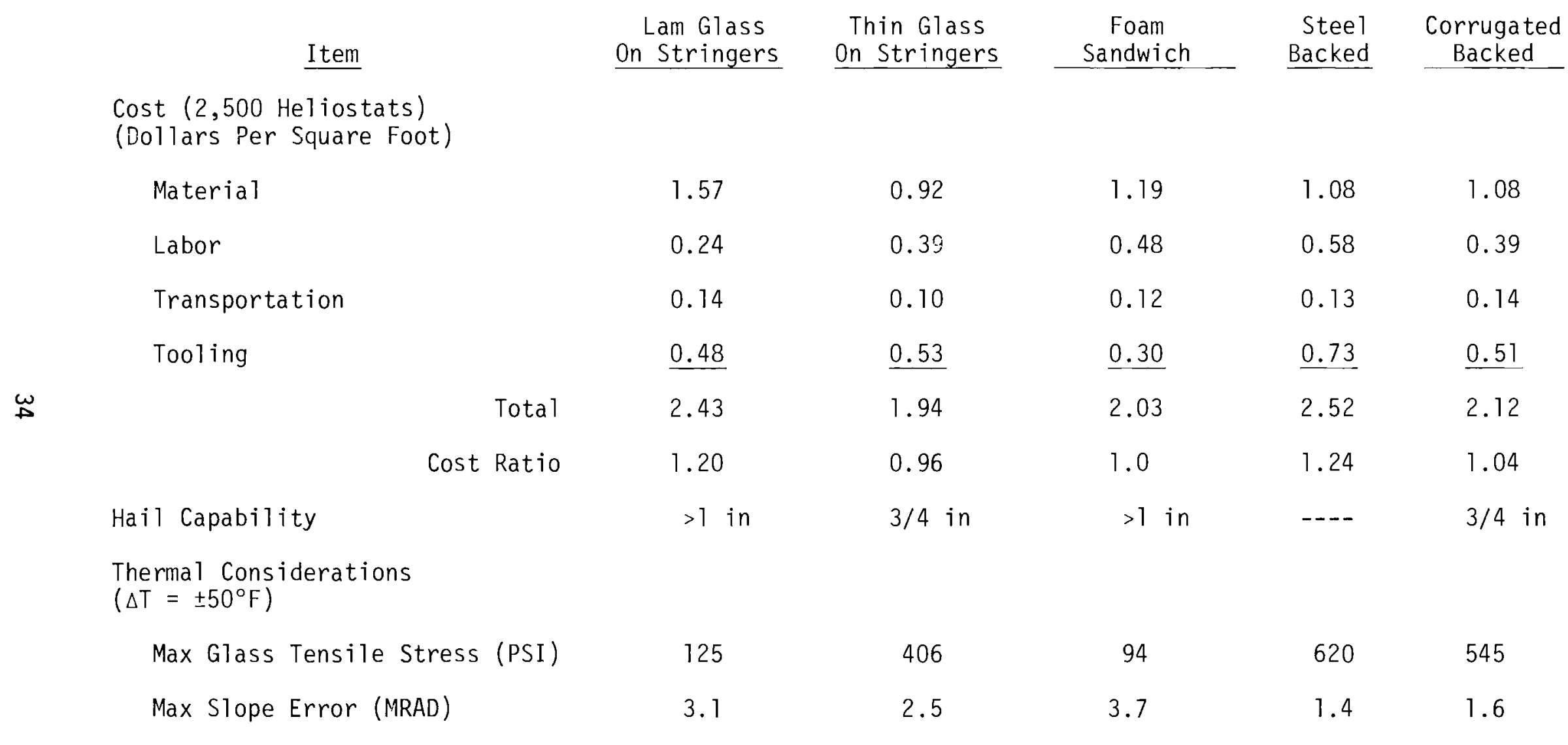


TABLE 2. Mirror Module Verification Tests

Test Type

Flatness

Stiffness

$\boldsymbol{w}$

Image

Performance

\section{Test Description}

Measure flatness of reflective surface at 40 to 60 points with panel supported at 4 points

Measure deflection of panel under line loading at edge and center with panel

supported at 4 points

Photograph reflected image

of mirror module at a

distance of about $30 \mathrm{ft}$

Measure reflectance efficiency of completed mirror modules with 1 deg Eppley pyroheliometer and MDAC digital image radiometer (DIR)

\section{Test Results}

Flatness within 0.020 in. overall is achievable

Stiffness consistent with beam and shear modulus test results

Proper materials and assembly methods result in no degradation of reflected image

Proper material and assembly methods result in no degradation of performance between mirror and mirror module 
.

. 


\section{"Development of Membrane Reflectors for Solar Central Receiver Heliostats" \\ M. Berry, Boeing Engineering and Construction}

The development of a membrane type reflector enclosed in a transparent plastic bubble for the central receiver heliostat is presented. The research programs resulted in a heliostat consisting of a Tedlar air supported closure seventeen feet in diameter, four mils thick, supported by a blower located in the steel base, and a fifteen foot diameter first surface aluminized mylar mirror.

The aluminized mylar reflector is stretched to $750 \mathrm{psi}$ tensile and then bonded to a foam surface. This particular mirror configuration has the characteristic that it will gravity deflect. For example, at 800 psi membrane stress, at near-horizontal, the focal length would be 7500 feet. The environmental effects on the membrane tension are shown in Table 1. The peak irradiance (relative to a perfect mirror) as a function of membrane tension indicates that the operating range for the reflector should be on the order of 750 psi.

Accelerated simulated sunlight tests of strength, elongation, and reflectance as a function of sunlight exposure were performed. For exposures on the order of 500 hours, the yield strength remains essentially unchanged ( $12 \mathrm{ksi}$ ) from an unexposed reflector. The elongation varies from $80 \%$ to $70 \%$. Also the reflectance degrades by $2 \%$ from $90 \%$. Creep tests indicate that after about 50 hours of operation, creep stabilizes and it remains stable for at least two years (test time period).

Two recommendations for future R\&D include maximizing specular reflectivity and improving the ability to predict useful lifetime. The specular reflectivity can be improved by using smoother, highly polished substrates and improved coatings and/or application processes. Lifetime prediction can be enhanced through more real time exposure testing and better accelerated to real time test correlations. 
TABLE 1. Environmental Effects on Membrane Tension

\section{Cause}

Temperature

Humidity

$\omega_{\infty}$
Effect

525 to $9751 \mathrm{~b} / \mathrm{in}^{2}$ $( \pm 30 \%)$

Less significant than temperature

Not significant
Remarks

$-20^{\circ}$ to $+120^{\circ} \mathrm{F}$

Tends to counteract

changes due to temperature

Constant, uniform tension component

$<1 / 10 \mathrm{~F}_{\mathrm{TY}}$ 
"Heliostat Glass Mirror Module and Low Iron Float Glass Evaluation"

C. L. Mavis, Sandia Laboratories of Livermore

The three glass mirror modules developed by Honeywe 11, Martin Marietta, and McDonnell Douglas during Phase I of the solar central receiver pilot plant have been evaluated at Sandia Laboratories. Of the three designs, the extruded polystryrene core mirror module developed by McDonnell Douglas is the preferred design. The tensile stress in the glass, caused by the expansion coefficient difference between the glass and the steel backing of the other two designs, is not believed acceptable. Mirror defocusing might be excessive for the McDonnel1 Douglas design at cold temperatures; however, this can be overcome by building the mirror with a slightly concave shape.

An adhesive aging program was started at Sandia in August, 1977 to evaluate adhesives and substrate materials. The evaluation consists of different environmental exposures to determine the bond strength of four adhesives applied to galvanized steel, sheet steel, epoxy-fiberglass, and mirror backing paint on metal surfaces. Two different metal primers were also included. Data are not available after six months exposure in four different environments. A total exposure of 12 months is planned.

Mirror modules have been built by Sandia that have an extruded polystyrene core (Dow's Styrofoam 1B). These mirrors have been tested for glass stress, contour change versus gravity, wind load, temperature, and susceptibility to hailstone damage. Extended thaw-freeze thermal cycling tests are in progress. The results agree with predicted values and with results obtained by McDonnell Douglas. A small change in mirror shape has occurred due to shrinkage of the adhesive during cure. Creep of the adhesive during its curing cycle is being investigated.

Low-iron glass is desired for the pilot plant. A special run of low-iron float glass was produced by PPG in January 1977. Mirror modules have been made using this glass by Martin Marietta, McDonnell Douglas, and Sandia. Although the iron content is not as low as desired, the mirror reflectivity is $88 \%$ versus an expected value of $91 \%$. This run of glass has a larger than 
normal wedge angle and is wavy in two directions. (It should be noted that the waviness appears to be a typical characteristic of thin (1/8 inch) float glass.) Preliminary analysis indicated that the spillage resulting from this waviness would be insignificant for the McDonnell Douglas pilot plant receiver but not for the $100 \mathrm{MW}$ plant.

Another candidate material for the pilot plant heloistats is a low-iron fusion glass made by Corning. Sandia has fabricated and is testing two $4 \times 4$ mirror modules constructed using this fusion glass and a styrofoam core. The glass is 0.060 inches thick and the mirror has a $95 \%$ total hemispherical reflectivity. The low loss in this glass is due to the low percentage of iron $\mathrm{Fe}^{2+}$, although the total iron content is higher than in low-iron float glass. 
"Summary of Solar Reflector Materials Properties"

R. B. Pettit, Sandia Laboratories, Albuquerque

Specular reflectance is essentially a measurement of the reflected beam intensity as a function of angular aperture. Most materials are described by a normal distribution so it takes two parameters to describe the distribution, beam intensity and beam width. Since these parameters are wave-length dependent, a solar average intensity and a solar average beam width must be used. The reflector scattering function, then, is the convolution of the input sun shape with the normal distribution of the reflector.

Theoretical maximum reflectance for three metals are shown in Figure 1. The calculated maximum solar reflectance is shown in the insert for both a base metal to vacuum interface and a base metal to glass interface. Notice that a glass second surface mirror is lower in reflectance than a base metal mirror by several percent.

A typical practical reflector consists of four layers: an outer protective layer, the reflecting surface, a backing layer of some thin metal sheet and a support structure that maintains the overall shape of the mirror. Each of these layers effects the specularity of the reflector as shown in Figure 2.

The characteristics of the three main catagories of solar reflector materials (silvered glass, metalized plastic films and polished aluminum sheet) are shown in Figure 3. Second-surface silvered glass mirrors can have solar-averaged specular reflectance values up to $96 \%$ with a root-mean-square (rms) reflected beam width less than 0.25 mrad. However, absorption in the glass, due primarily to iron impurities, can substantially reduce the solar reflectance value. The amount of the reduction depends on the glass thickness and impurity level. Microsheet glass is so thin ( $0.1 \mathrm{~mm}$ ) that absorption in the glass is negligible. In addition, this glass can be elastically formed into a parabolic trough concentrator with a small radius of curvature. 


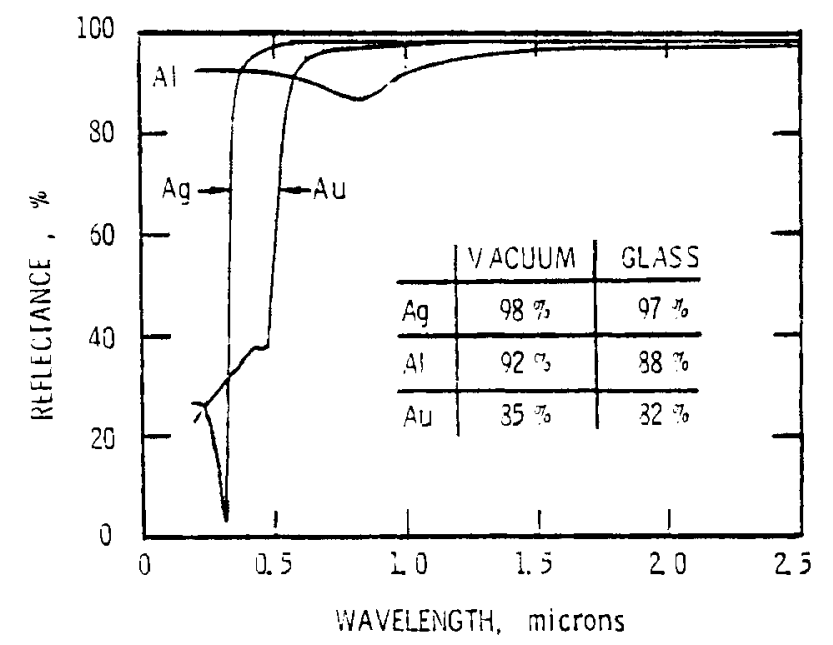

FIGURE 1. Calculated Theoretical Limit of Solar Reflectance for Gold, Aluminum and Silver

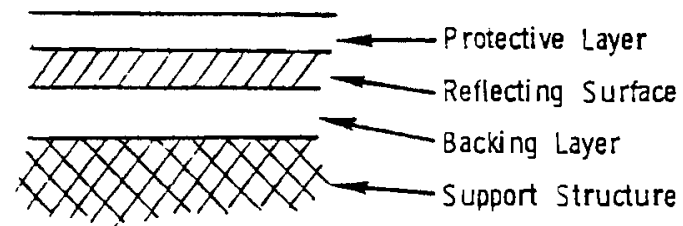

Protective Layer

- Abscrotion

- Scattering

- Surface Roughness

- Parallel Surfaces

Reflecting Surface

- Surface Roughness

- Deposition Process

Backing Layer

- Surface Roughness

- Lamination Technique

Support Structure

- Surface Roughness

FIGURE 2. Typical Reflector Construction and Scattering Parameters 


\section{R.FI.CCTANCE}

- Fvaporated, Chem. Deposited Silver: $R_{s}=95-97 \%$ - Absorption In Glass (Fe $e^{+2}$ a 1 micron)

- Low iron glass

- Thin glass

- Control oxidation state of $\mathrm{Fe}\left(\mathrm{Fe}^{+3}\right)$

\section{SPECULARITY}

- Typically o 0.5 mrad

- Index Variation (Composition)

- Thickness Variations

- Surface Stope Errors

- Sheet, float, fusion

\section{ENIVIROIMENTAL.}

- Good Alurasion Resistance

- UV Resistance

- Silver Adhesion; Edge Protection

- Corrosion (Moisture Plus Dirt)
- Vacuum Deposited $A_{g}\left(R_{S}=45 \%\right)$ Al $\left(R_{S} \approx 88 \%\right)$

- Alsorption In IR $(\because 1$ micron $)$

- Typical of Aluninum: $\mathrm{K}_{\mathrm{S}}(2 *)=85 \%$

- Anodized Protection [ilit

- Surface Texture Metallized Surface

- Scattering Within Fizm

- Laminating raraneters (adhesive, substrate) Obtained o $\leqslant$ 1. Onrad (3M FEK - 163)

- Surface Roughness (Polishing Technique)

- Anodized Film

- Orientation Dependence

- 5 - 15\% loss At 17 uràd

- Poor Abrasion Resistance

- Good Aurasion Resistance

- Possible UV Degradation

- Good UV stability

- Moisture Penetration

- Static Charge

\section{FIGURE 3. Characteristics of the Three Main Categories of Solar Reflector Materials}


Environmentally, glass possesses good abrasion resistance and uv stability, although long term protection for the silver needs further study.

The specular reflectance properties of metallized plastic films depend upon the texture of the metallized surface, the optical properties of the plastic film, and the lamination process and surface roughness of the substrate. The surface texture of plastics can range from that of smooth glass (rms beam width 0.25 mrad) to lightly abraded, which causes significant scattering. Laminated films have been obtained with a RMS beam width of less than $1.0 \mathrm{mrad}$. Environmentally, plastics are subject to abrasion from both blowing dirt particles and from mechanical cleaning. In addition, uv stability, moisture permeation, static charging and delamination may be important long term degradation effects.

Polished aluminum surfaces are usually characterized by a significant amount of large angle scattering which reduces the intensity of the specular beam. This scattering results from residual scratches, pits, or polishing marks on the reflecting surface. In addition, the reflected beam profile can be anisotropic due to polishing marks extending in one direction. The aluminum surface is usually protected from environmental degradation by an anodized oxide film.

Several protective coatings are beginning to be developed and applied to reflector materials. They are ARC $90 \% \mathrm{SiO}_{2}$ (Dow Corning), FEK-163 for aluminized acrylic (3M), Alglas for aluminum sheet (G.E.), multilayer films (O.C.L.I.), Lucite AR (Dupont), and glass resin type 650 (Owens-I1linois). When applied to a metallized plastic film, the coating offers improved abrasion resistance and protection of the reflecting film. In some cases, the coatings are applied directly on top of the aluminum or silver reflecting surface. 
"Testing of Solar Reflective Materials - Experiences vs Requirements"

J. E. Gilligan, J. E. Brzuskiewicz, J. Madigan, IIT Research Institute

The objectives of this paper were to provide some basic properties information on solar reflector materials. It related the results of weathering tests, identifies materials problem areas, discusses measurement techniques and shows specific optical characterization measurements.

Emphasis was given to bidirectional reflectivity measurements. Measurement geometries and typical data are shown in Figures 1 and 2. Basically a known incident beam is reflected from a sample material and the reflected beam analyzed in order to characterize the material's specular reflectance properties.

The basic mirror configuration consists of six layers. These are: a transparent superstrate, a reflective surface, a first and a second protective flash, an adhesive layer, and a support structure substrate. A11 or any of these layers may be present in a real mirror.

IITRI has examined six materials which are under consideration for use as solar reflectors. These are: a metallized acrylic film, a rigid acrylic second surface mirror, and three anodized aluminum mirrors. Table 1 shows some solar weighted hemispherical reflectance data for both cleaned and uncleaned samples. Some general conclusions which resulted from the study are listed in Figure 3. 
BIDIRECTIONAL-NORMAL $\left(\rho_{n}\right)$

$\theta_{i}: 0^{\circ}$, fixed

$\theta_{r}: 0^{\circ} \longrightarrow 90^{\circ}$
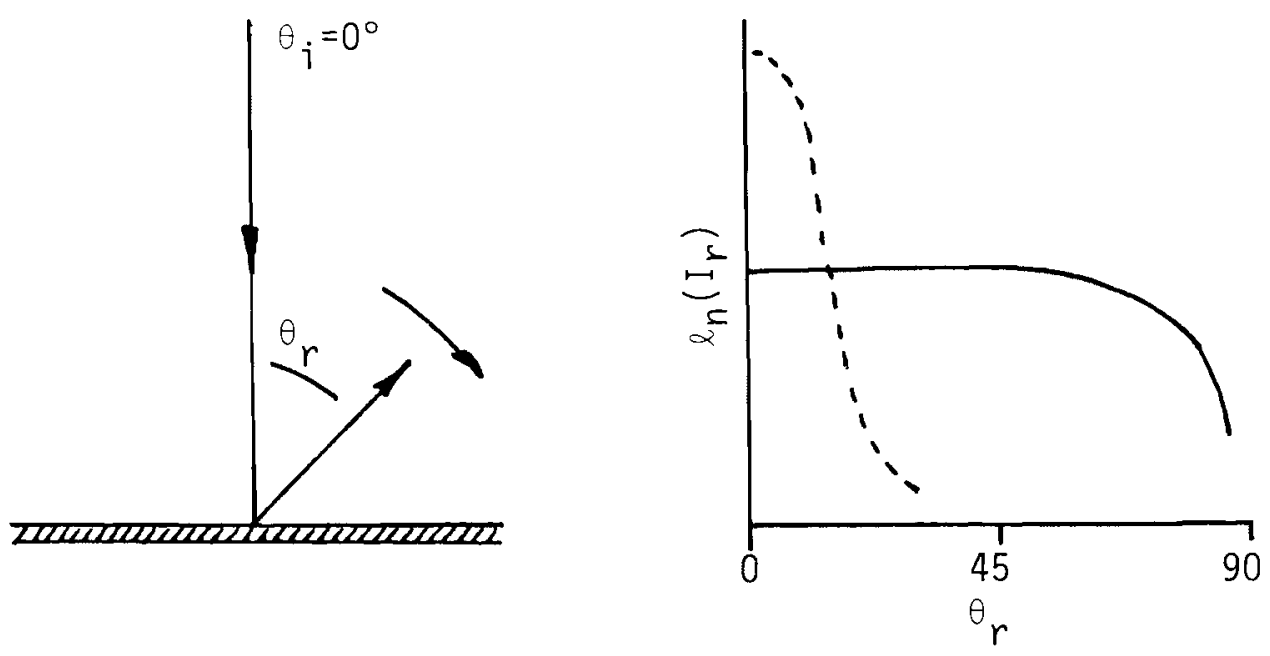

BIDIRECTIONAL-BISTATIC $\left(\rho_{B}\right)$

$\theta_{r}=-\theta_{i}$
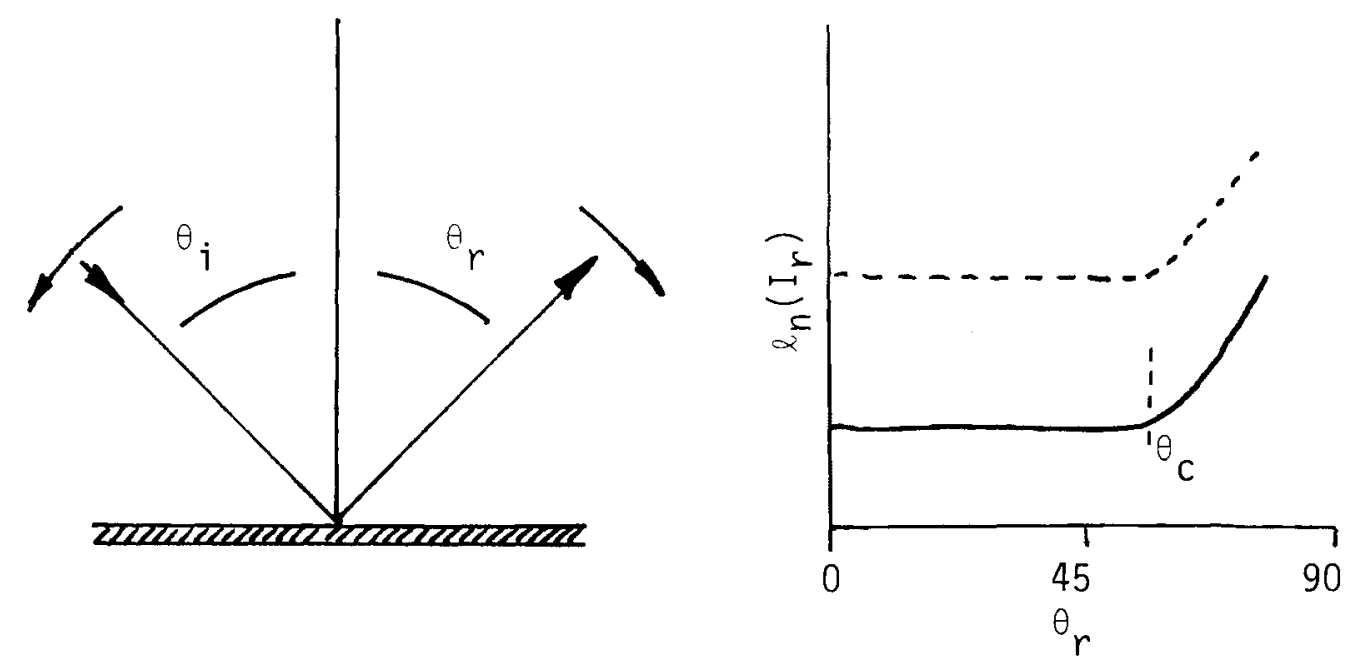

BIDIRECTIONAL-GENERAL $\left(\rho_{G}\right)$

$\theta_{i}:<0^{\circ}$, fixed

$\theta_{r}: 0^{\circ} \rightarrow 90^{\circ}$
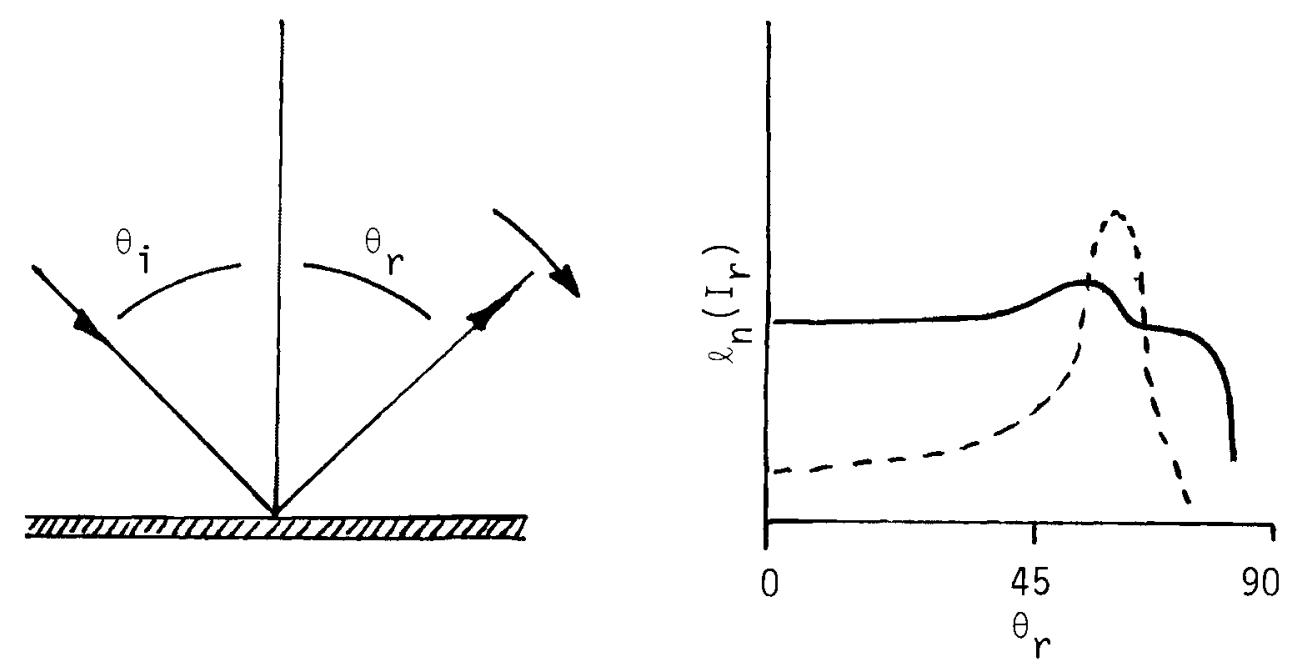

FIGURE 1. Didirectional Reflectance Measurement Geometries and Typical Data for Specular (----) and Diffuse (-) Materials 


\section{BIDIRECTIONAL-DIFFERENCE BISTATIC $\left(\rho_{\triangle B}\right)$}
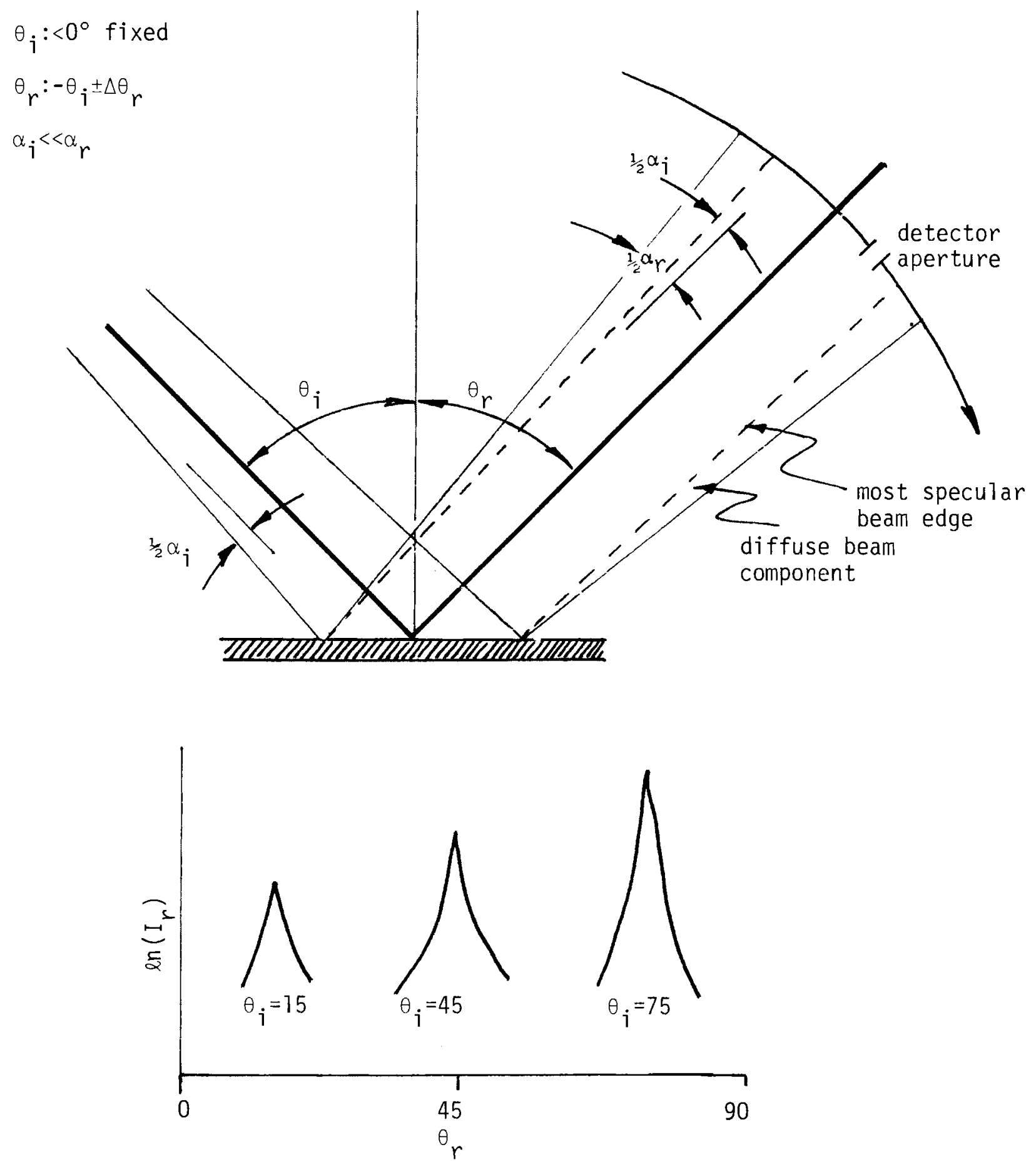

FIGURE 2. Bidirectional Reflectance Geometry for the "Delta Bistatic" Measurement and Typical Data 
TABLE 1. Air Mass Two Solar Weighted Hemispherical

Reflectance Data

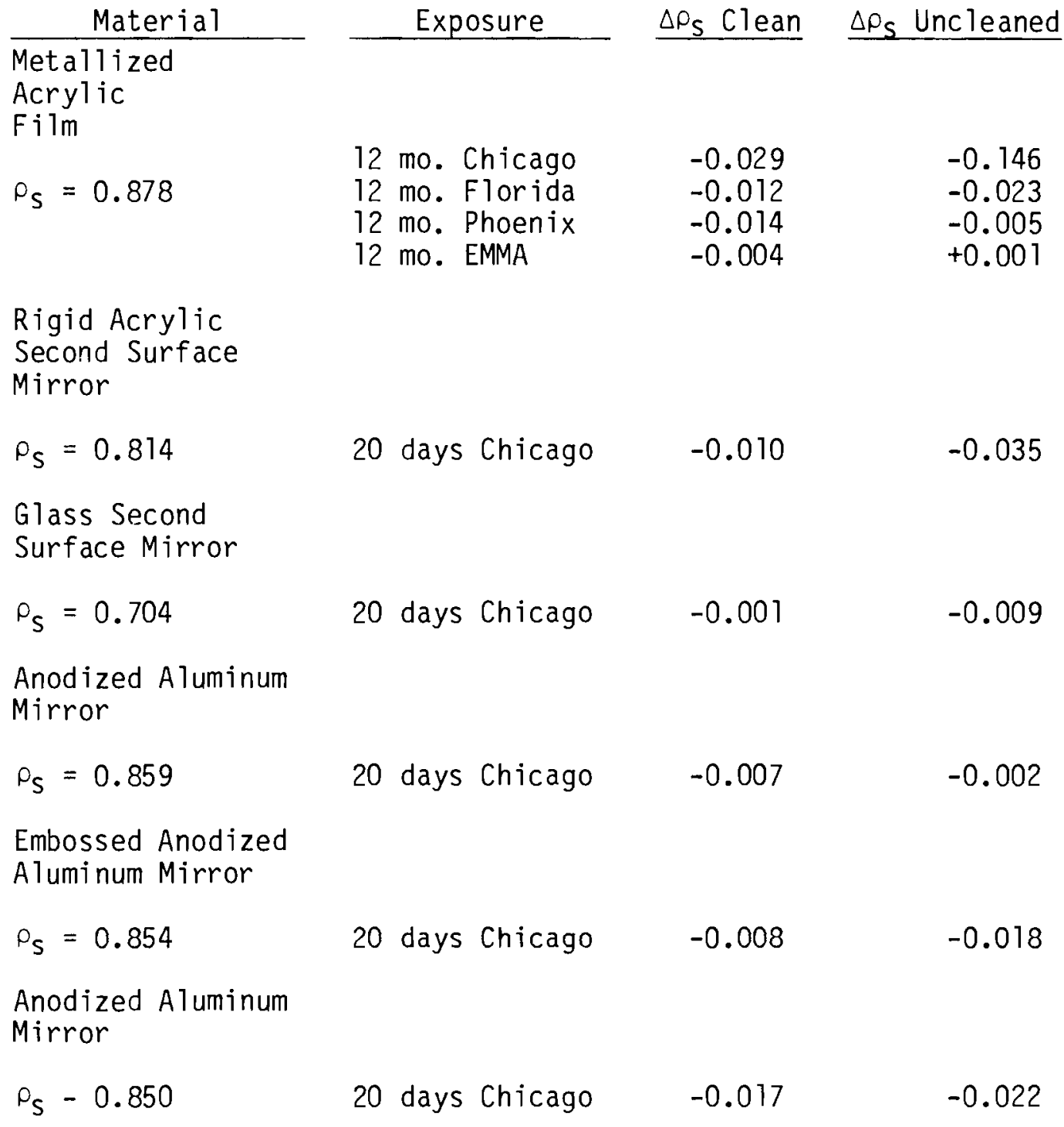




\section{MATERIALS}

- Optical Degradation varies with site and duration

- Well maintained controls, unexposed, sometimes change with time

- Weathering of Superstrate is most important

- Dust Effects are critical - vary with site, season, and duration

- Natural "Ageing" occurs in some materials

- Directional Reflectance Characteristics are very sensitive to morphology of transparent and reflective surfaces

- Some materials have more of a problem with dust than others

\section{MEASUREMENT TECHNIQUES}

- Must Know:

Substrate Flatness

Superstrate Surface Texture \& Roughness Characteristics

- Must Measure:

Hemispherical Reflectance $R_{H}(\lambda)$

Bidirectional Reflectance $\rho_{B}, \rho_{\Delta B}$ (one or more $\theta_{i}$ )

- Must Specify:

Measurement Geometries and wavelength $\alpha_{i}, \theta_{i}, \Omega_{i}, \lambda$

\section{GENERAL}

- Cleaning is VIP but material-specific and highly site dependent

- Accelerated Test Validity - not yet established

- Lifetime Predictions - very complicated

\section{FIGURE 3. Conclusions}


.

. 
"The Simulation of Solar-Thermal Energy Conversion Systems"

L. Schrenk, University of Pennsylvania

Analytical techniques have been developed which are applicable to the design and analysis of solar-thermal energy conversion systems. The central problem is essentially the efficient concentration of diffused solar energy into a small area of space. The general process and typical losses are illustrated in Figure 1. A typical solar-thermal energy conversion system consists of a cylindrical cavity with a heat exchanging fluid flowing through it. The efficiency of the system is the product of the reflectance of the mirror, the collection efficiency and the cavity efficiency. Performance curves for cavity receivers have been calculated.

The particular uniqueness of the analytical techniques described is that they are based on an extended finite-sized source and that the resultant radiation transfer is analyzed using cones, either infinitesimal or finite, rather than optical rays as the basic vehicle for energy transport. The method includes provisions for evaluating the effects of both concentrator surface errors and orientation errors. The accuracies of the calculated flux distribution is limited only by the ability to experimentally define the actual system in sufficient detail. The codes are written in APL and are available nationwide from the Scientific Time Sharing Corporation System. 


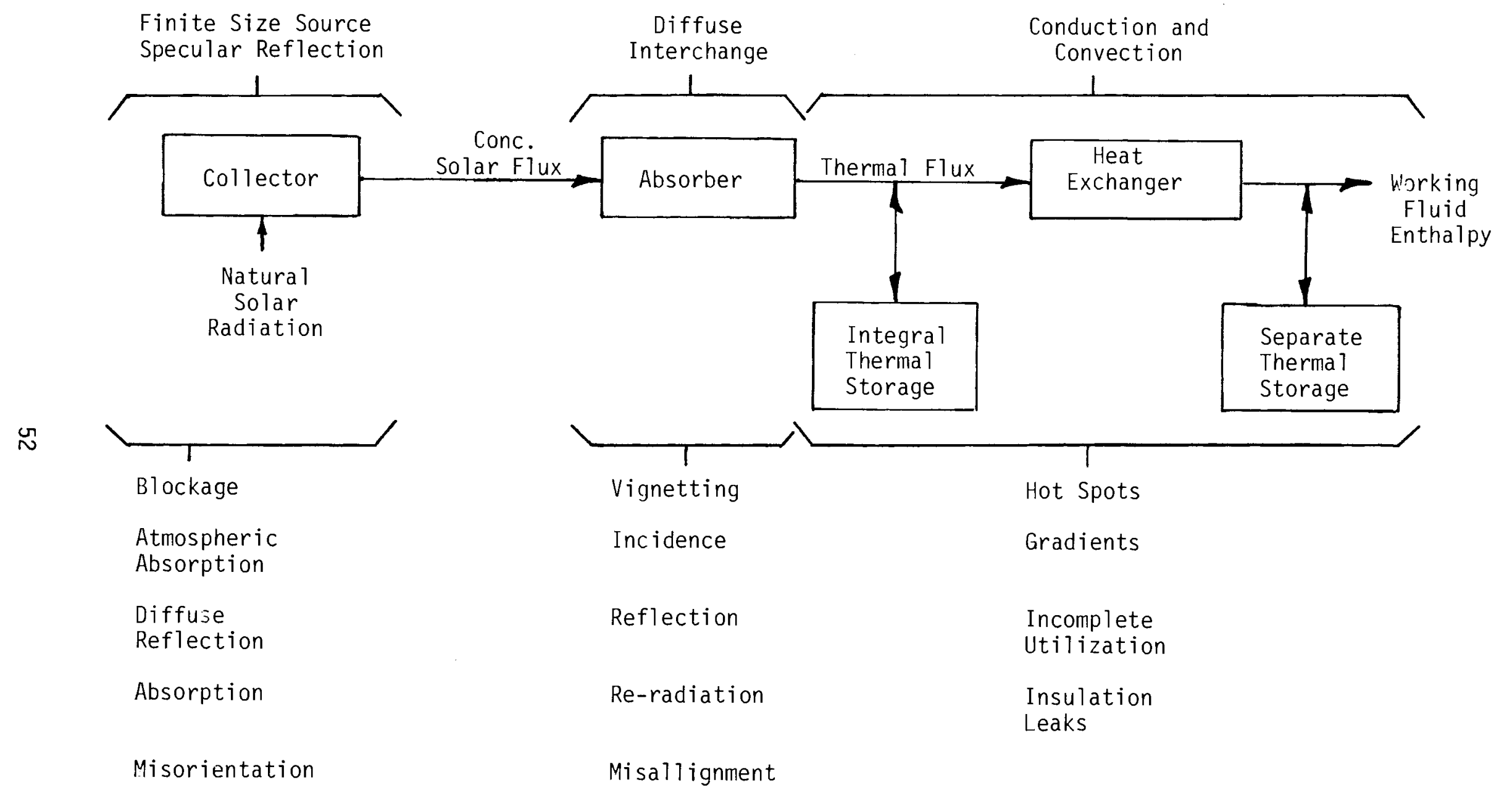

FIGURE 1. Energy Conversion and Losses 
"The Effects of Environment on Glass Surfaces"

P. B. Adams, Corning Glass Works

The transmittance of a pristine glass surface is difficult to monitor if the surface is subjected to dirt accumulation and weathering. A glass surface changes with weathering, soil adhesion, and cleaning. The question now becomes how to minimize and/or control these changes. Surface weathering can occur in the form of absorption of water concurrently with other airborne particulates. Leaching or ion exchange and etching can occur. These processes result in alkali being pulled out of glass and onto the surface which eventually etches it, pits it, and causes the surface to degrade. Silica glasses are prone to alkaline attack, whereas low silica glasses are susceptible to attack from acids as well. Other factors which contribute to weathering are moisture, temperature change, UV radiation, chemical agents, stress, mechanical erosion, and biological agents.

Table 1 shows the relative adhesive force for four particle sizes ranging from 0.5 to $500 \mu \mathrm{m}$. The smaller the particle, the stronger the force holding it to the surface, and the harder it is to remove the particle from that

TABLE 1. Adhesive Forces Versus Particle Size(a,b)

\begin{tabular}{cr}
$\begin{array}{c}\text { Particle } \\
\text { Size } \\
\text { (Micrometers) }\end{array}$ & $\begin{array}{r}\text { Relative Adhesive } \\
\text { Force in Air } \\
\text { (G's) }\end{array}$ \\
\cline { 2 - 2 } 500 & 2 \\
50 & 200 \\
5 & 20,000 \\
0.5 & $2,000,000$
\end{tabular}

(a) The above table assumes a linear regulation for adhesive force (dynes) as a function of diameter.

(b) The forces can vary by orders of magnitude depending on molecular adhesion, softness, etc. 
surface. Some particles can also adhere to a surface by a glue type mechanism because of a reaction with the glass perhaps, or because of other contaminants that have come along and actually stuck the material on there.

Trying to correlate accelerated lab tests and natural exposure tests is difficult. Your never get $100 \%$ correlation. If you get $50 \%$, you are doing fairly well.

When it comes time to clean a surface, the first thing you have to know is what it is, what is the soil. A surface that is really corroded, and the silicate structure destroyed, presents a completely different cleaning problem than a soiled unweathered surface. We need to design the simplest cleaning process that removes the soil and leaves an acceptable surface. Some cleaning options are aqueous and nonaqueous solvents, detergents, and physical/mechanical methods.

Some common cleaning mistakes are trying to take somebody else's procedure and put a new twist on it without really understanding what you're doing to that surface. One can make the surface dirtier than it was initially by using a cleaner that stays there as a contaminant and helps to attract further soil. 
"Dust Buildup and Cleaning of Solar Reflectors"

R. S. Berg, Sandia Laboratories of Albuquerque

The objective of the project is to develop techniques that are capable of reducing dirt accumulation on solar energy optical surfaces, such as mirrors, lenses and windows. The approach to the problem is to identify and estimate the relative importance of the mechanisms that contribute to dirt deposition and to examine ways that these can be modified to affect dirt accumulation. The project consists of four tasks:

1. Develop an understanding of the mechanics of dirt deposition and adhesion, and of the elements of cleaning alternatives.

2. Develop equipment for depositing dusts in a controlled laboratory environment and develop instrumentation for characterizing the dust.

3. Evaluate and characterize techniques that are capable of reducing dirt accumulation on solar energy optical surfaces.

4. Evaluate potentially successful techniques from task 3 in roof top and scaled-up tests in the various solar test facilities.

The mechanisms of dust adhesion that have been identified are listed in Table 1. Some techniques which might be used effectively to decrease dust accumulation are shown in Table 2.

Cleaning effectiveness depends on the technique used, the environmental conditions, and the amount of time the mirror has been exposed. Several continuous and periodic cleaning techniques have shown promise. Continuous cleaning using electrostatic repulsion has been tested in laboratory experiments and was shown to reduce dust accumulation. These experiments were performed in a low velocity $(0-25 \mathrm{~m} / \mathrm{s})$ atmospheric wind tunnel fitted with a dust injector capable of injecting $10^{4}$ times as many optically important particles as are present in the normal aerosol. Periodic cleaning using high pressure sprays of up to 10,000 psi have been used to clean dirt from outdoor test samples. Tap water sprays at pressures above $500 \mathrm{psi}$ seem to be equally effective and recover about $95 \%$ of the reflectance loss from dirt buildup. 
TABLE 1. Mechanisms of Dust Adhesion for Deposited Dirt Particles (for du 10-20 $\mu \mathrm{m}$ )

\begin{tabular}{|c|c|c|c|}
\hline Mechanism & $\begin{array}{c}\text { Relative Force } \\
\text { Size }\end{array}$ & $\begin{array}{c}\text { Affecting Material } \\
\text { Property }\end{array}$ & Applications \\
\hline Gravity & $1 \mathrm{~g}$ & Mass & \\
\hline Electrostatic & $\gtrsim 1 \mathrm{~g}$ & $\begin{array}{l}\text { Surface (coating) } \\
\text { conductivity }\end{array}$ & $\begin{array}{l}\text { Conducting polymers, } \\
\text { precipitators }\end{array}$ \\
\hline Charge double layer & $\approx 100 \mathrm{~g}$ & $\begin{array}{l}\text { Contact potential or } \\
\text { difference in electron } \\
\text { affinities }\end{array}$ & \\
\hline Surface energy & $\approx 100 \mathrm{~g}$ & Solid surface relaxation & $\begin{array}{l}\text { Surfactants, teflon } \\
\text { coating }\end{array}$ \\
\hline Capillary force & $\geq 10,000 \mathrm{~g}$ & Fluid surface relaxation & Detergents \\
\hline Chemical/physical & $?$ & Chemical activity & \\
\hline
\end{tabular}


TABLE 2. Techniques Which Can Affect Dust Accumulation

\section{Action}

Inverting while inactive

Aerodynamic streamlining

Electrostatic biasing

Vibrating the surface

Thermally induced air currents

Flowing air

\section{Comment}

Relative importance of sedimentation in particle settling

Prevention of turbulent eddies and dead spots Utilization of boundary-layer phenomena

Several hundred volts with normal electric field rejects particles

Boundary type of phenomenon used on astronomical telescopes

Boundary type of phenomenon used on astronomical telesceopes 
Several common detergents have been examined. Detergents with low pressure sprays generally must be used on short intervals, less than two weeks, or they lose their effectiveness. 


\section{"Mirror Waviness in Solar Central Receiver Heliostats"}

\section{W. R. Delameter, Sandia Livermore Laboratories}

Part of the mirror module evaluation program is to look at techniques for measuring mirror waviness, the effects of waviness on heliostat performance and the cost impact of mirror waviness on a $10 \mathrm{MW}_{\mathrm{e}}$ pilot plant and the $100 \mathrm{MW}_{\mathrm{e}}$ commercial plant.

Mirror distortion is measured by the grid-image technique. A grid is photographed both directly and as reflected in the mirror under test. The mirror distortion is then evaluated by comparing the two grid photographs.

Glass waviness with a wavelength of between 5 and 15 inches has been observed in mirrors which are being considered for solar central receiver heliostats. The peak mirror normal slope error is estimated to be on the order of one or two milliradians.

The cost tradeoffs seem to be between manufacturing flatter glass and adding more heliostats to compensate for spillage losses. The present thinking leans towards the latter option. The calculated effects of this waviness on the average power spillage for simulated 10 and $100 \mathrm{MW}_{\mathrm{e}} \mathrm{plants}$ are shown in Figures 1 and 2. 


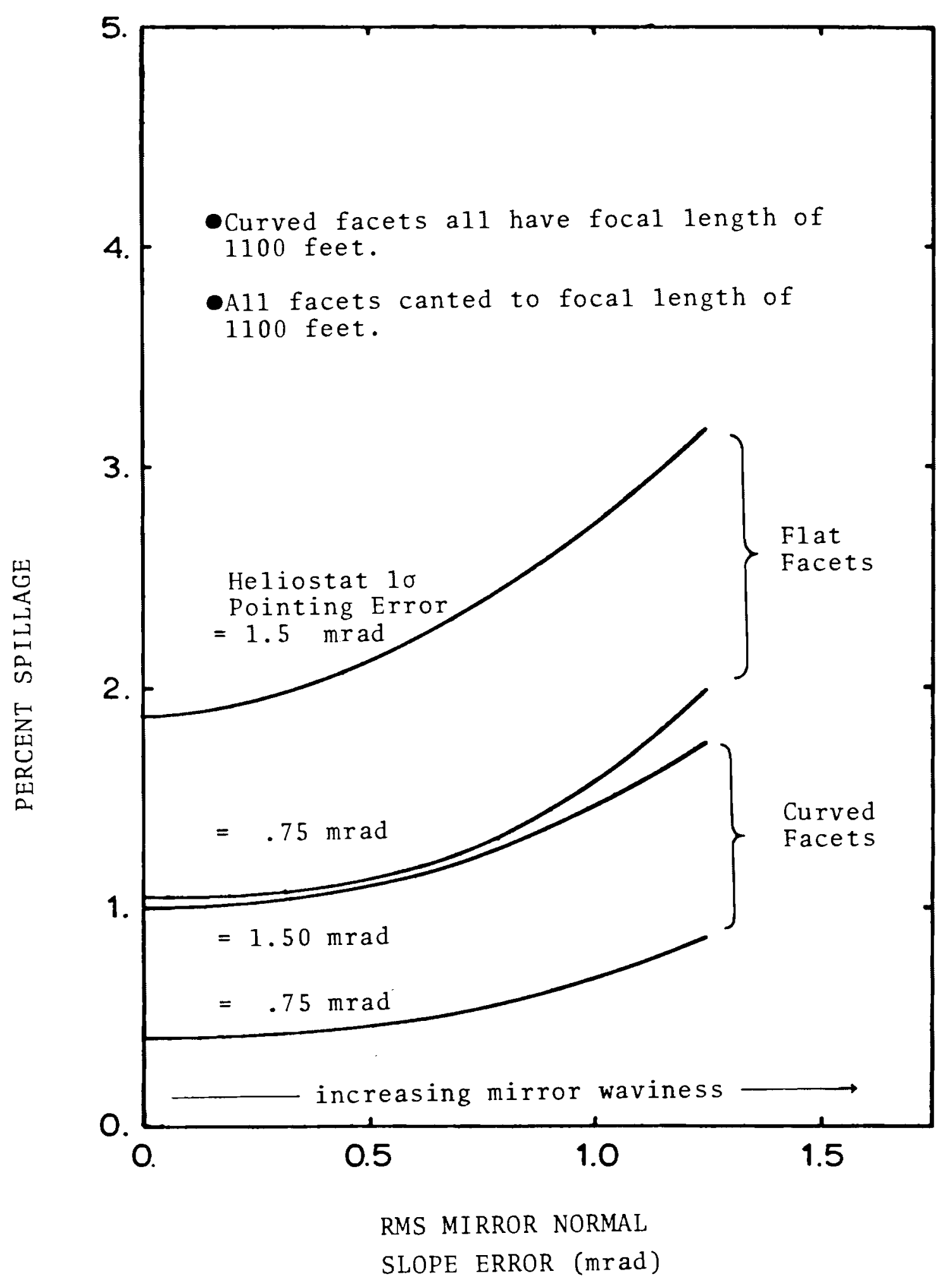

FIGURE 1. Yearly Average Fower Spillage Versus Mirror Waviness for 10 MWe Pilot Plant 


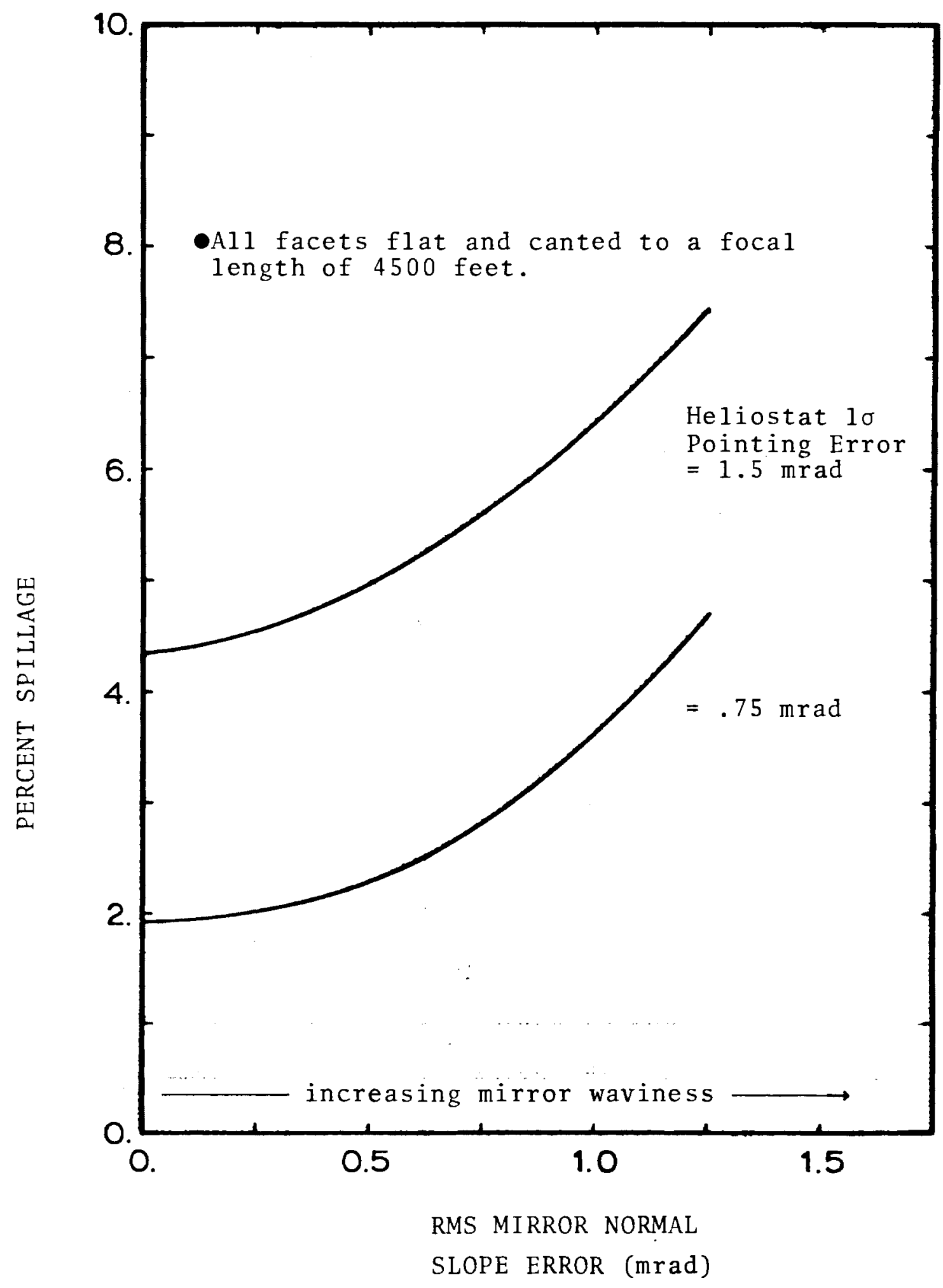

FIGURE 2. Yearly Average Power Spillage Versus Mirror Waviness for 100 MWe Commerical Plant 


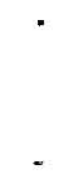


"Augmented Solar Energy Collection Using Different Types of Planar Reflective Surface, Theoretical Calculations and Experimental Results"

D. P. Grimmer, K. T. Zinn, K. C. Herr and B. C. Wood Los Alamos Scientific Laboratory

The performance of flat plate solar collectors can be substantially improved by the use of planar reflective surfaces having the appropriate orientation and reflective properties. The work done in this paper differs from that of other investigations principally in that an attempt is made to describe the reflective properties of surfaces in more generalized terms than simple direct or simple diffuse. Most real surfaces possess a combination of specular-like and diffuse-like reflectivities. The reflectivity properties of a given surface can be measured in the laboratory as a function of incident and reflected angles, and these measured reflective properties can be used in the computer model to predict the increase in collector performance with such a reflector.

Outdoor tests of a given reflector can be avoided, and yet it is possible to make an estimate of the reflector's contribution to the collector's overall performance. Figure 1 shows the measured and predicted results for a specular mirror test. The experimental data which tends to be greater than the predicted values for early morning and late afternoon is possible due to a polarization phenomena.

Figure 2 gives the results of the study. Shown is the predicted total daily intensity plotted as a function of time of year for various collector/ reflector configurations. All the collectors that were compared are single glassed and their horizontal reflectors have a length that is three times the collector height. 


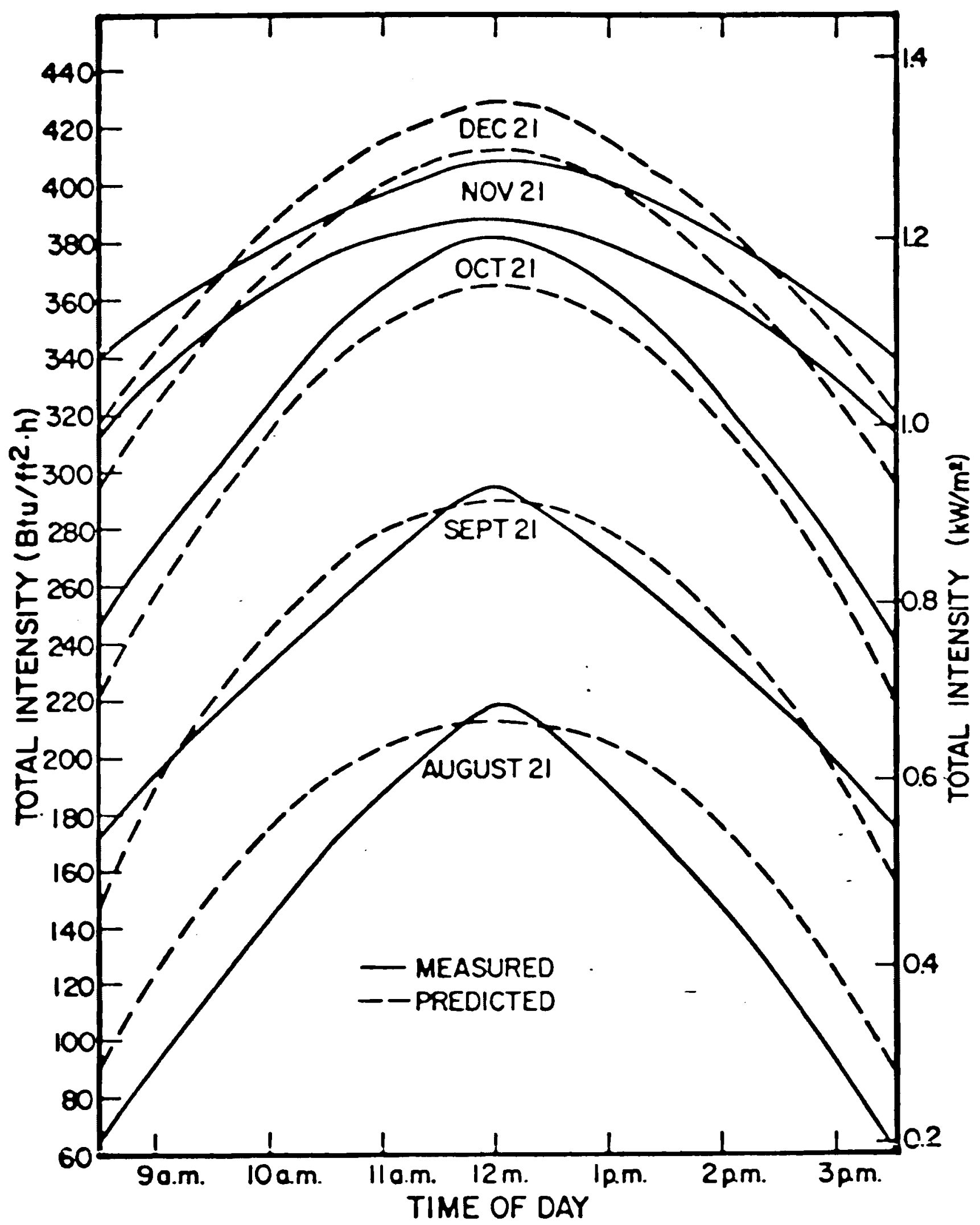

FIGURE 1. Results for Specular Mirror for Outdoor Measurements (-) and Computer Simulation (-.-) 


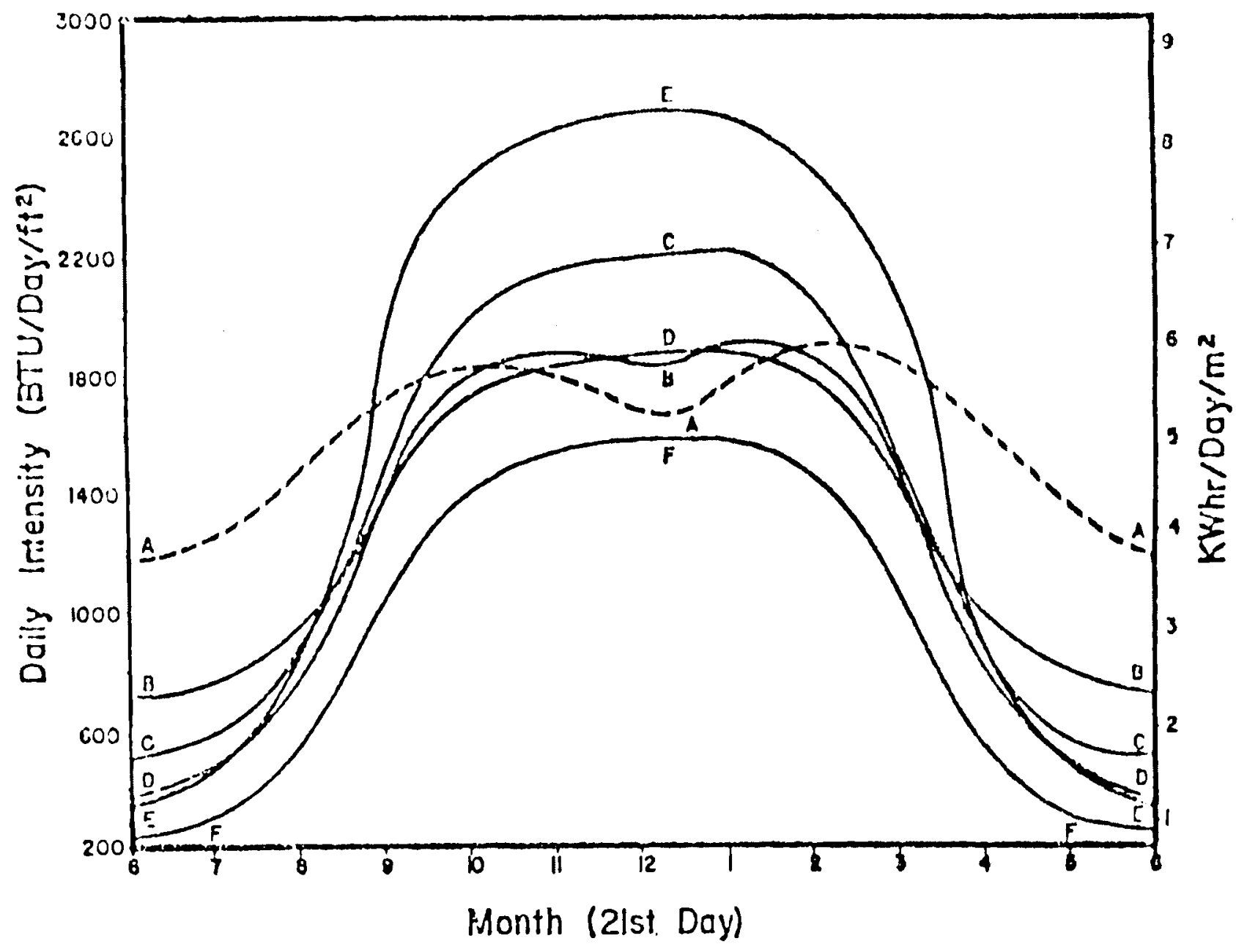

FIGURE 2. Relative Predicted Insolation Gains for Various Reflector/Collection Combinations. Predicted total daily intensity is plotted as a function of time of year for various collector/reflector configurations. Curve $A$ (dashed) is for a $55^{\circ}$ tilted collector without reflector. Curve $B$ is for a $90^{\circ}$ tilted collector with white-paint reflector $(\rho=0.73)$. Curve $D$ is for a $90^{\circ}$ tilted collector with silver-paint reflector $(\rho=0.52)$. Curve $E$ is for a $90^{\circ}$ tilted collector with specular-mirror reflector $(\rho=0.80)$. Curve $F$ is for $90^{\circ}$ tilted collector without a reflector. The collectors are single-glazed, and the horizontal reflectors have a length that is three times the collector height. 


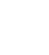

. 
"Field Evaluation of Solar Mirror Survivability"

R. M. Bethea, P. E. \& M. T. Barrigen, Texas Tech University

Multiple samples of eight candidate solar concentrator mirrors, including both first and second surface types, were deployed 7 feet above ground level for eight months. The mirrors and materials tested included samples of: Scotchal 5400, Alza, RAM acrylic, Glass, Carolina Mirror, Plexiglass, Kinglux $\mathrm{CH} / 40$, and Donnelly Mirror. The exposure period included the majority of the 1977 dust storm season in west Texas. Additional samples were deployed at the 95-100 feet elevation on a radio transmitter tower. The samples were evaluated at regular intervals and after every major dust, hail, or thunder storm in the area. All materials suffered severe damage except the Carolina Glass Co. Mirrors. Polymeric materials failed due to warping and crazing; some glass mirrors failed due to disintegration of the reflective (second) surface. One first surface material failed due to hailstone pitting. Other materials failed due to blistering of the reflective surface or the inability to withstand $1 / 2$ to 1 inch hail. 
.

. 


\section{"Hail Impact Tests of Solar Mirrors" \\ M. L. Smith, Texas Tech University}

Hail impact tests were conducted on materials which were candidates for solar concentrator mirrors. Testing was done with iceballs simulating hailstones shot from a compressed air cannon. Samples included $1 / 8$ inch and $3 / 16$ inch float glass supported at the edges, 0.04 inch, $3 / 32$ inch, $1 / 8$ inch, and $3 / 16$ inch glass bonded to a honeycomb substrate. Breaking velocities were determined for iceball diameters ranging from 1 inch to 2 inches. The 1/8 inch glass on honeycomb substrate had an average breaking velocity of 128 miles/hour with 1-1/2 inch iceballs and 76 miles/hour with 2 inch iceballs. other materials tested included plexiglass panels and central receiver materials coated with Pyromark paint.

Characteristics of hailstorms in the area of the proposed concentrator site were examined. Hailpad data were used to obtain hail frequencies, impact angles, and maximum diameters. 
, 
"Solar Reflective Materials at the Solar Pump"

F. Munoz and R. Almanza, National University of Mexico

Research is being carried on in four principal areas: water heating, water distillation, grain drying, and conversion to electric energy using a photothermal-mechanical process.

For the solar pump, solar energy is reflected into the absorber tube (six meters long and $2.54 \mathrm{~cm}$ in diameter) using parabolic-cylindrical reflectors $\left(\right.$ area $=30 \mathrm{~m}^{2}$ ). The absorber tube is covered with a selective surface using the Ebonal process and surrounded with an evacuated Pyrex glass tube. Pressurized water is injected inside the absorber tube where it is converted to steam. The steam then runs a one-kilowatt piston engine.

Some reflective materials which have been developed at the University include second surface evaporated aluminum on acrylic, electropolished aluminum, vacuum evaporated aluminum on stainless steel, and chrome and nickel plated polished brass. Because of degradation due to loss of adhesion, shrinkage, broken and peeling edges, and low reflectivity of the other materials, thick acrylic aluminum mirrors were selected for use in the solar pump. 

"An Integrated Materials Development Approach to a Reflective Structural System"

W. D. Mitche11, Solaramics, Incorporated

Solaramics is currently engaged in a materials activity for the development of a reflective system composed of very thin microglass bonded to a foamed glass structural substrate.

The advantages seen in foam glass are that it is thermally compatible with the glass mirror reflector system. It can be utilized as a structural substrate to carry the load as well as support the glass mirror. It is also producible at a very low cost.

The production approach used today is a closed mold. However, the material is amenable to a continuous ribbon process. As a continuous ribbon process, it will be possible to produce the material with a variable density and also to hotform the material. By mechanically working the material as it issues from the ribbon process, it can be formed into a parabolic shape.

The design concepts possible include a variable density sandwich. This panel would have a very dead skin on the surface with a very light-weight cellular core to achieve the advantages of a structure sandwich material. It's also possible to incorporate a hardware cloth or a wire reinforcement in the foam glass and achieve a slight amount of compression. This allows fracture control to prevent complete destruction of the material in case it's broken.

In conjunction with this foam glass development, Solaramics is pursuing a thin glass or microglass reflector approach. The advantage of the microglass reflector is high transmission and good environmental resistance, and low production costs. By virtue of its thinness, a very high reflective efficiency can be achieved. The reflector can also be focused and contoured by static deflection. For the normal trough or paraboloic concentrator, ten mil glass is readily contourable without exceeding nominal working stresses. 
Because of the difficulty of handling and working with the thin material, it will be advantageous to produce the material as an integrated process wherein the metallization of the surface of the material is done while the glass surface is still pristine. This avoids some of the problems associated with cleaning and handling and preparation for the normal silvering operation. 


\section{"Enhanced Reflectivity Aluminum"}

D. M. Trotter, Jr., N. W. Ashcroft, R. A. Buhrman, A. J. Sievers and J. W. Wilkins, Cornell University

An aluminized reflective surface is inexpensive and durable, but because the reflectivity of aluminum is significantly less than $100 \%$, about $10 \%$ of the power incident on a solar energy collector is lost in making just one reflection from its surface. By using impurity stabilization and/or alloying, it should be possible to produce an amorphous phase of aluminum which is stable at room temperature. Such an amorphous material would inherently lack the interband electronic transitions which depress the reflectivity of crystalline aluminum films, and if increased electron scattering can be minimized the materials should exhibit a substantially improved reflectivity.

By evaporating a very thin silver layer onto the aluminum, its reflectivity is improved. In the limit where the thin silver layer becomes thick, the reflectivity becomes that of silver. However, silver is not durable. Putting an aluminum layer over the silver makes the coating more durable as well as increasing its reflectivity above that of alumina deposited on aluminum. The problem is stabilizing the amorphous structure at room temperature. 
.

. 
"Sunlight Concentration for Silicon Rod Solar Cells"

G. L. Ball III, Monsanto Reserarch Corporation

Solar cell devices, Figures 1 and 2, were made using diffused junctions on the surface of $4 \mathrm{~mm}$ silicon rods together with nontracking, "ideal" trough concentrators. Two embodiments of the ideal concentrator design were studied: metallized opaque plastic reflective forms and internally reflecting clear plastic castings. Combined solar cell/concentrator efficiencies of $10 \%$ were measured and efficiencies of $12 \%$ are projected. 

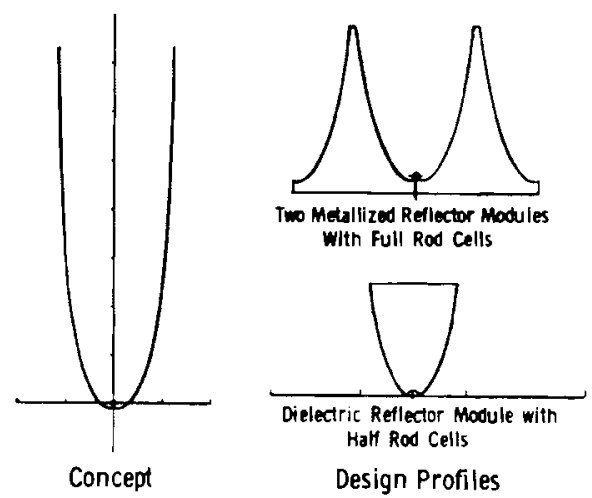

FIGURE 1. Concentrators for Rod Solar Cell
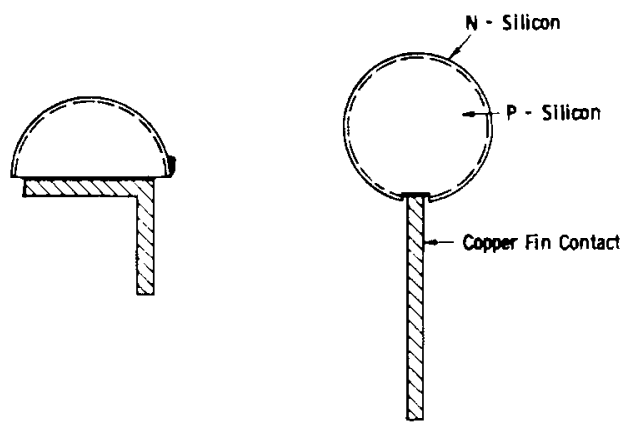

Half-Rod Design

Full Rod Design

FIGURE 2. Rod Solar Cells 
"The Development of Standards for Spectral/Specular Reflectance" J. Richmond, National Bureau of Standards

The NBS is planning to prepare some standards for spectral/specular reflectance. They will tentatively be prepared as second surface mirrors on $2 \mathrm{~mm}$ thick fused quartz. The quartz will have a good optical polish on very parallel surfaces. Aluminum will be deposited on one surface and backed up with a second sheet of fused quartz about 3-4 mm thick.

The standards will be calibrated over the spectral range from 250-280 nanometers up to about 3.5 micrometers for near-normal incidence. For perhaps ten selected wavelengths in this range, the standards will be calibrated for angles of incidence of fifteen, thirty, forty-five, and sixty degrees from normal. The price for these standards is expected to be something on the order of $\$ 400-\$ 500$ each. Hopefully, they will be available before the end of the year.

NBS is also publishing a text entitled "A Self Study Manual for Optical Radiation Measurements." It should be of interest to everyone concerned with optical measurements. 


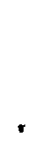




\section{WORKING GROUP SESSIONS}

\section{INTRODUCTION}

In order to provide some direction to the working group discussion, a questionnaire was prepared and distributed to the workshop participants. The questionnaire was in two parts.

The first part was in the form of several matrices to be filled in by the participants which detail the current state of knowledge regarding reflector materials types versus their known or estimated properties. The properties of interest included optical, mechanical, durability/weatherability, maintenance and lifetime economics, and finally the fundamental limitations of the materials and areas for potential improvement. A copy of the first part of the questionnaire is reproduced in the appendix at the end of this section of the report. A summary of the responses received from the matrix questionnaire is given below.

The second part of the questionnaire was more philosophical in nature. It included questions designed to stimulate discussions concerning the relevance of certain avenues of research. Among other things, the participants were asked to prioritize areas of R\&D they think merit further support. The questions that were asked and a summary of the responses are included below.

In the afternoon of the second day of the conference, the participants broke into pre-assigned working groups of 10 to 15 people to facilitate discussions of the questionnaire. Each group was assigned a group leader to record the responses and encourage further discussion. 


\section{SUMMARY OF RESPONSES TO MATRIX QUESTIONNAIRE}

The following is a summary of the responses of the participants to each of the sections of the matrix questionnaire. Included also are comments that were generated by the questionnaire that were common to a large number of the participants.

1. Optical Properties

- Some data is available on reflectance, transmittance and specularity. However, much of the data is inadequate.

- A complete compilation of the present data base is needed.

- A variety of measurement techniques are used; the results are not easily compared.

- Most available standards are not directly applicable to solar systems.

- Standardization of terminology and measurement techniques for reflector characterization is necessary. The need is acute for definitions for specularity and slope error.

- Small business needs government lab support to defer the high capital costs of measurement and testing equipment and to coordinate and standardize results.

2. Mechanical Properties

- There was very little data collected at the workshop.

- Properties and measurement procedures are generally well understood.

- ASTM standards are adequate in most cases.

- Impact testing is one area that requires a better basic understanding and more research effort.

- Ice ball and steel ball tests do not simulate hail. This is presently a good R\&D area.

- Any standards or specifications developed should take into account regional differences.

- Standardized tests are needed for thermal distortion and rigidity. The largest uncertainty with present techniques is inferring dynamic properties from static tests. 
3. Durability/Weatherability

- Very little data is available.

- Questions were raised as to validity of available data and testing procedures.

- Standard test methods are necessary.

- The topic requires government support. Basic R\&D is needed to correlate accelerated testing with real time environmental exposure.

- A good, accessable compilation of available data base is needed.

4. Maintenance Factors and Lifetime

- Some basic work on dust interactions is being done. More is necessary. Areas of $R \& D$ should also include cleaning and inhibiting dust adhesion.

- Very little reliable information is available on life expectancy of materials.

5. Economics, Fundamental Limitations and Areas of Long Range Potential for Improvement of Performance

- Little information is available.

Although this section of the questionnaire was designed to contribute significantly to the solar reflector material data base, it did not do so. The response to the specific questions in the matrix was very limited. No significant or new data was disclosed. 
The majority of the workshop session was spent discussing the eight general philosophy questions distributed to each of the participants. The questions and a summary of the responses are given below:

QUESTION 1: Is it possible to incorporate all of the reflector materials R\&D into developmental programs or is a separate R\&D program to address long-range questions and gener ic problems necessary?

RANGE OF GROUP RESPONSE:

- No Government Sponsored R\&D in Private Industry (Preference: Purchase Agreement if Product is Successful) to

- Independent R\&D Program Essential

TABULATED RESPONSE:

- Necessary $\quad \sim 50 \%$

- Marginal $\sim 15 \%$

- Not necessary $\sim 35 \%$

EMPHASIS OF PROGRAM:

- Communication

- Mechanisms for Technology Transfer

- Relevance

- Long Range (>10 years)

PROBLEM AREAS:

- Incentives for Commercialization

- Proprietary Interest Protection for Manufacturers.

QUESTION 2: Assuming that a reflector materials program will be developed by DOE, prioritize the following list of potential program elements: (0-no importance; 1) low priority; 2) medium priority; 3) high priority). 
TABULATED RESPONSE: In order of highest priority first with average score listed at the left.

2.8 Weatherability/Durability Measurements

2.8 Improved Field Measurements

2.5 Cleaning Techniques

2.6 Standardization

2.3 Understanding Dust Adhesion*

2.3 More Field Measurements

2.2 Understanding Degradation Mechanisms

2.1 Material Characterization*

1.9 Improved Laboratory Measurements*

1.8 New Materials

1.7 Process Development*

1.6 Process Refinement*

1.4 Fabrication Refinement

1.4 Fabrication Development

0.9 More Laboratory Measurements

*Large standard deviation present in the data

QUESTION 3: Do you feel that standards or, at a minimum, guidelines need to be established for characterization of reflector material performance? If so, what areas should have highest priority? What standards already exist that are appropriate for reflector materials?

RANGE OF RESPONSE :

- Specify Performance of the Final Product Only to

- Standards are Needed for Weatherability, System and Subsystem Performance. 
TABULATED RESPONSE:

- Standards Necessary: $>90 \%$

EMPHASIS ON:

- Optical Properties

- Weatherability/Durability

- Testing Laboratories

- How to Use Standards

ASTM standards good starting point for many problems, especially mechanical properties.

QUESTION 4: Is there adequate information available concerning the appropriate testing of reflector materials? If not, what needs to be done to make that information available?

RESPONSE :

- $\quad$ No $>90 \%$

- Need help of Government Labs for:

- coordination and standardization of results

- deferring high capital costs of measurement and testing equipment

- Areas Need Support:

- optical measurements

- environmental testing

- correlation of accelerated aging with real time testing

- computation of adequate data base

QUESTION 5: Do we need to know and/or specify surface roughness, its source (i.e., intrinsic or process related), and its effect on optical properties? Or can surface roughness be accounted for in other parameters (i.e., specularity, figure, etc.)? Comments.

RESPONSE :

- Mixed to both Questions

- Comments Included:

- not needed if specularity data exists

- could have impact on weatherability

- may be useful for process control or QA 
QUESTION 6: Is impact testing necessary? If so, how can this measurement be accomplished?

RESPONSE :

- Wide Range of Opinion from None Necessary to Mandatory

- General Comments Included:

- ice ball test no good, need simulated hail

- location of impact on sample important

- ASTM and military should have some data

- good basic program needed

- better definition of tests are required

- standard tests should be adopted

QUESTION 7: Are hardness/toughness measurements meaningful? If so, what should be accepted as a standard geometry for these tests? If not, what tests are appropriate that can be related to abrasion resistance?

RESPONSES :

- Such Tests are of Dubious Significance

- Standard Tests May Be Useful

- Good R\&D Area

- General Comments Included:

- regional dependence should be accounted for

- available ASTM standards applicable in some cases

- more research indicated

QUESTION 8: Do you feel that you personally have an adequate understanding of the nomenclature and basic techniques of a) optical measurements? b) mechanical properties measurements?

RESPONSE :

- Understand Optical Measurements, No 60\%

- Understand Mechanical Properties Measurements, Yes 60\%

- General Comments Included:

- standard terminology required especially for optical measurements

- must also be educated on how to use a particular measurement 
VII. APPENDICES

Appendix A - Matrix Questionnaire

Appendix B - List of Participants 


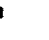


APPENDIX A

The following pages contain a reproduction of the matrix portion of the materials data questionnaire. 


\section{System Parameters Vs. System Type}

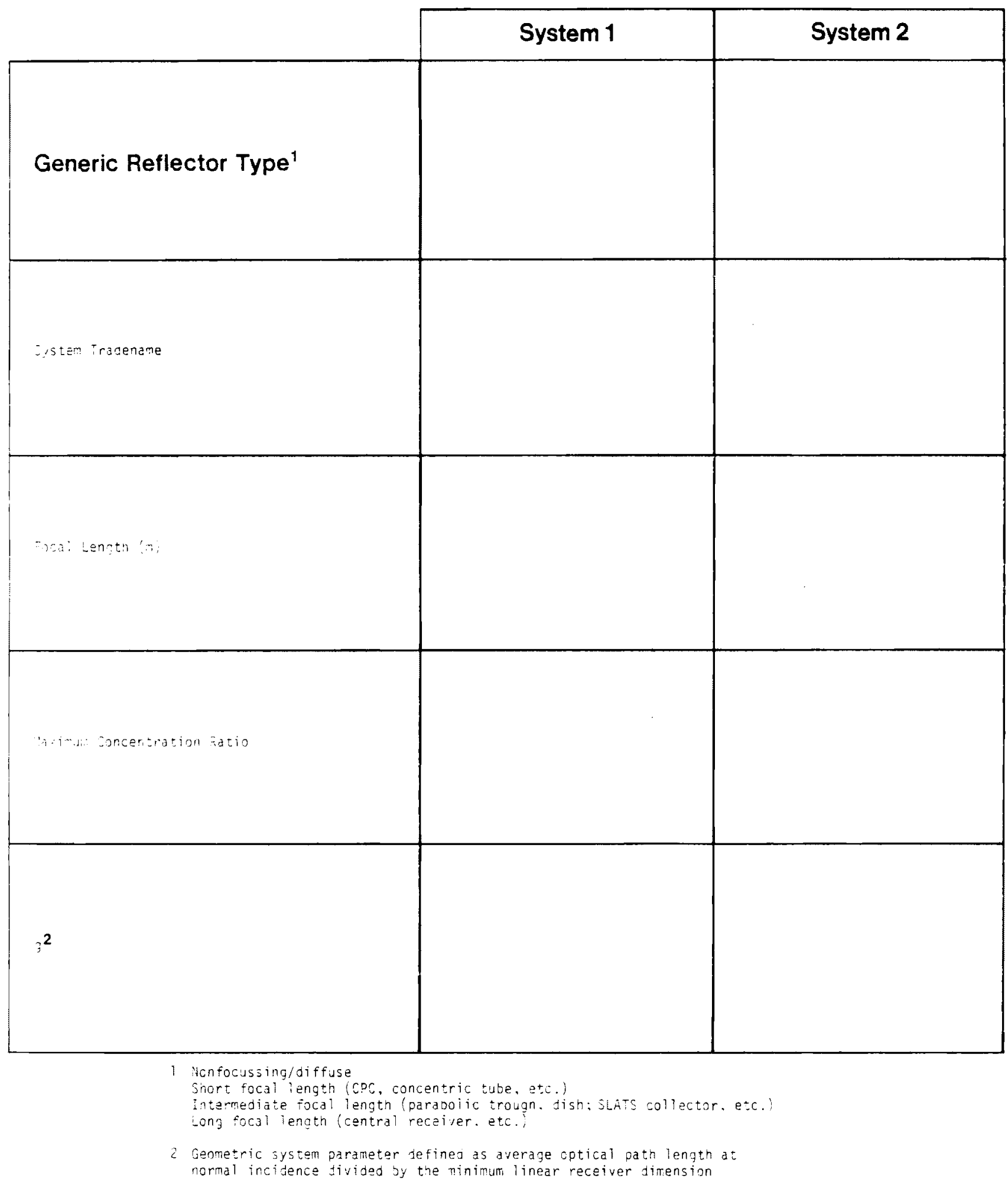

$A-1$ 


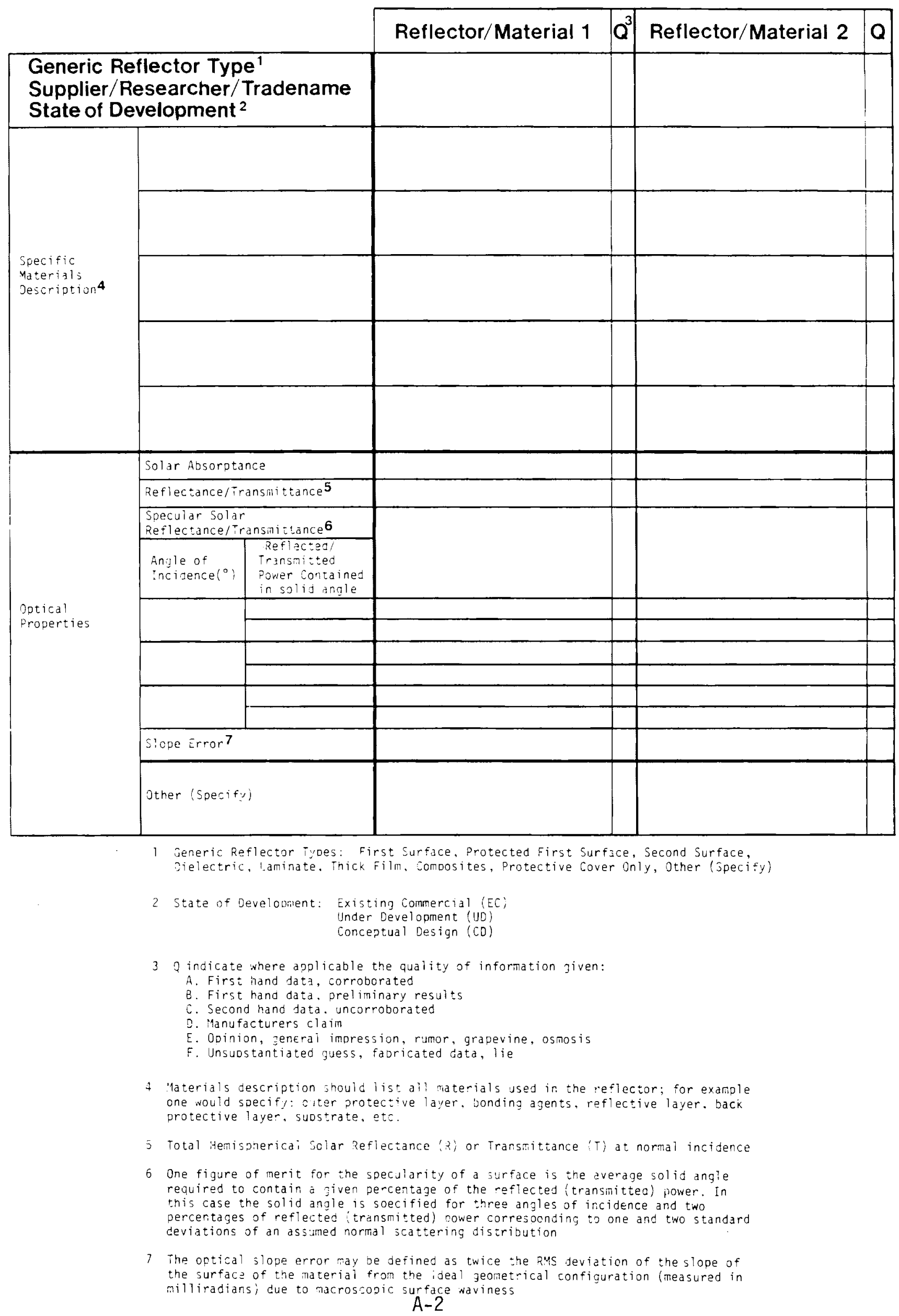




\section{MECHANICAL PROPERTIES}

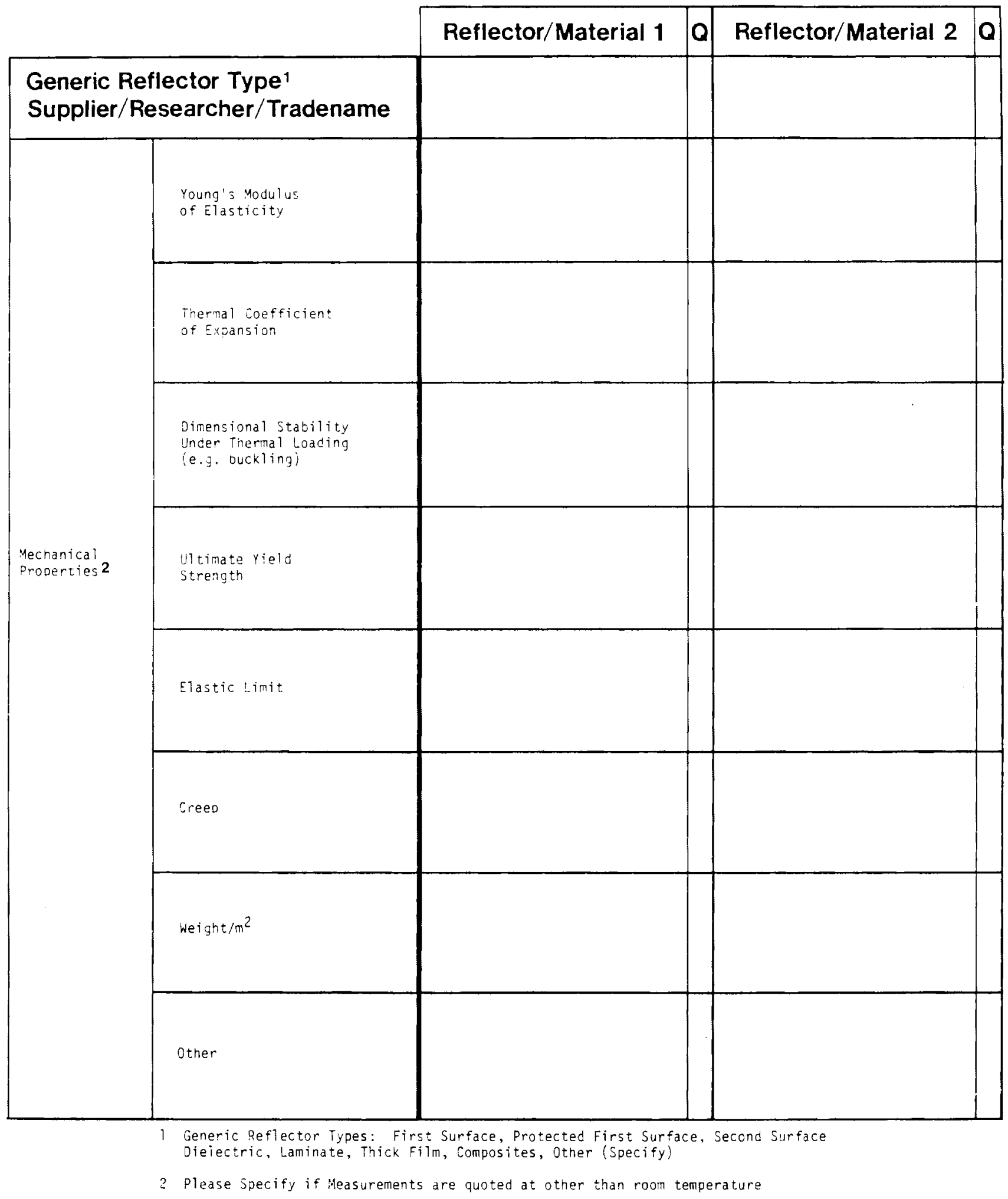




\section{DURABILITY/WEATHERABILITY}

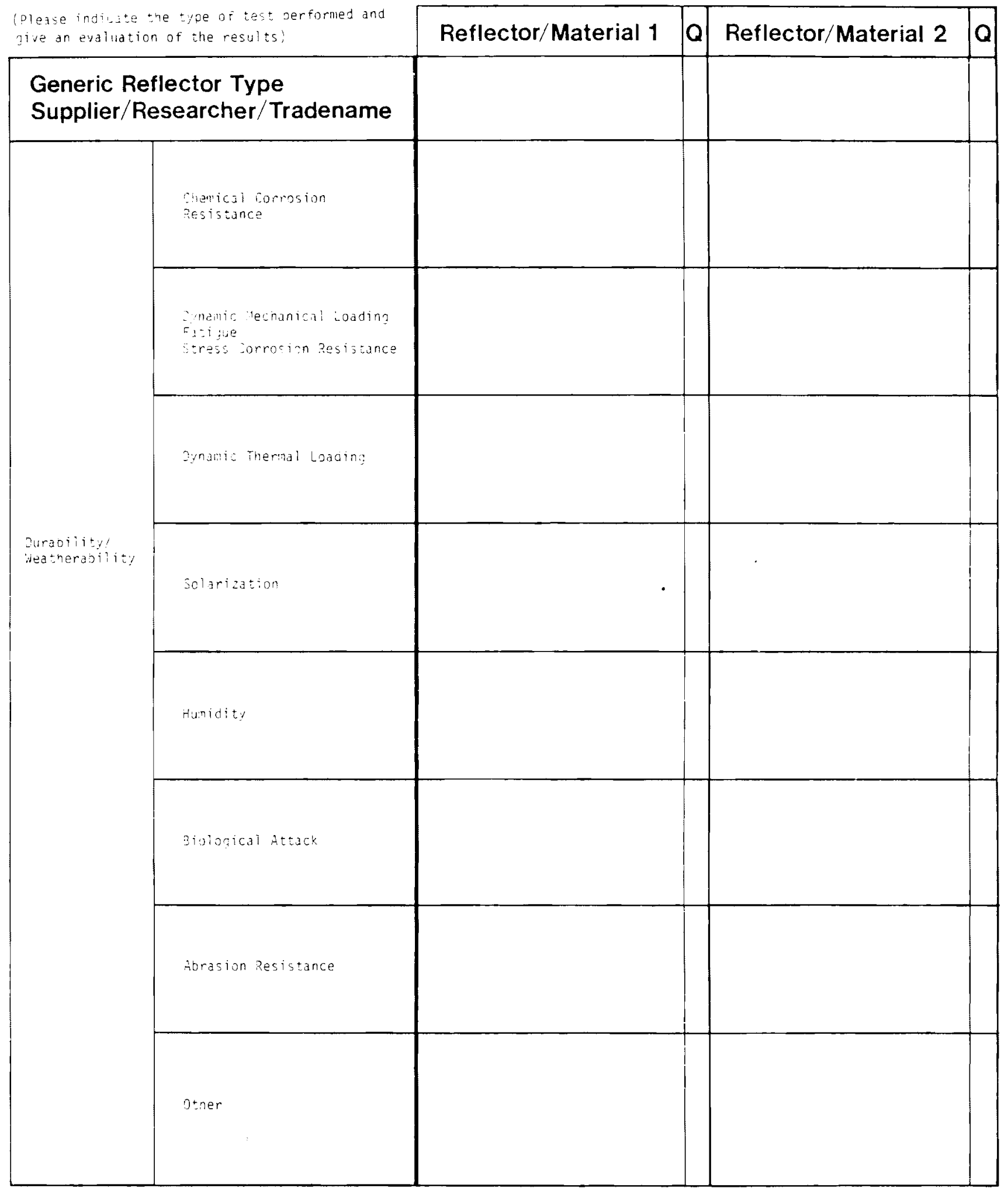

Ueneric Reflector ipes: First Surface, Protected firs: Surface, Second surface, diejectric, Laminate.

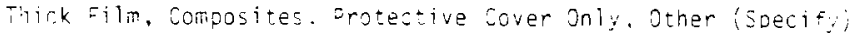




\section{MAINTENANCE FACTORS AND LIFETIME}

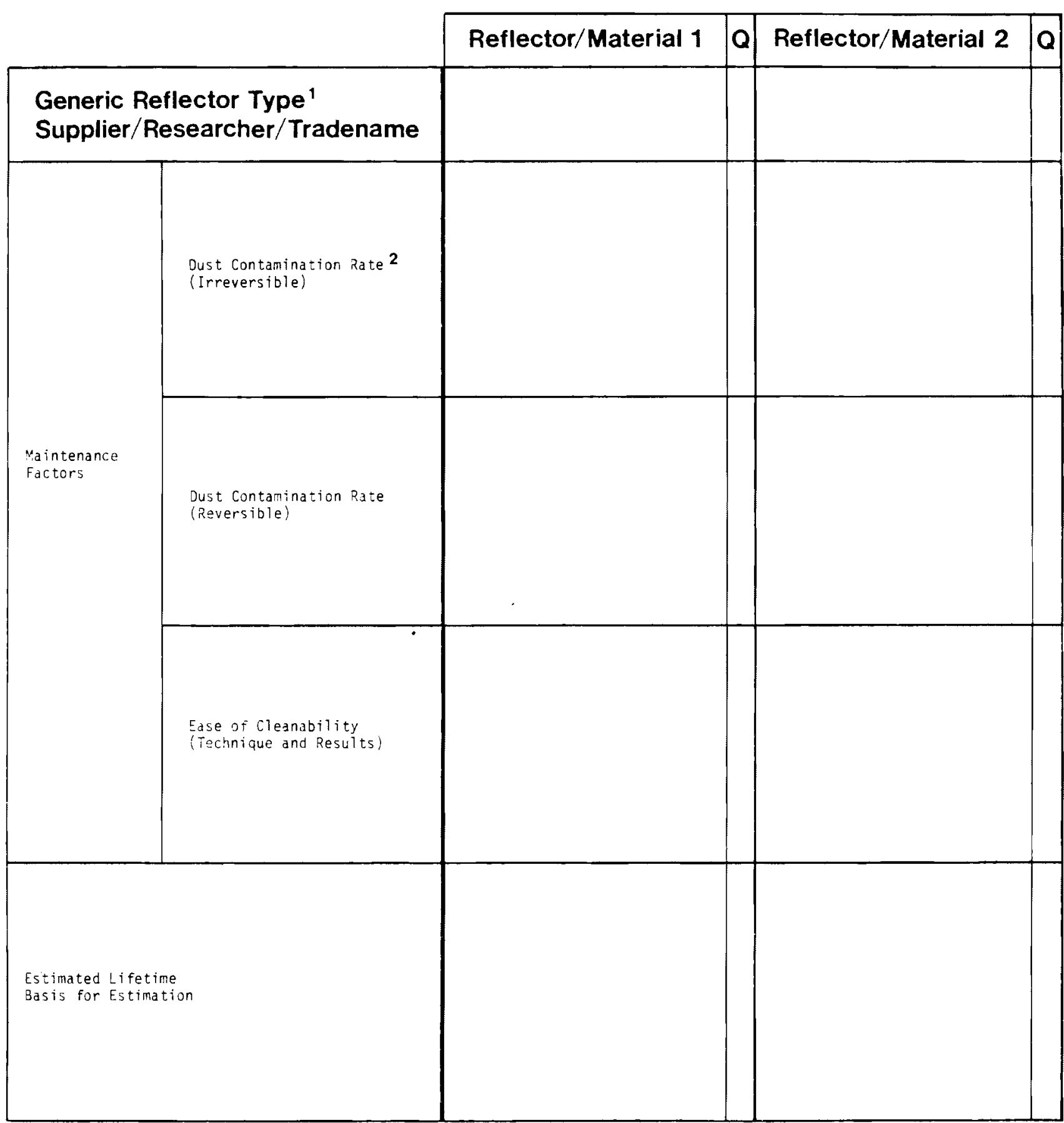

i Generic Reflector Types: First Surface, Protected First Surface, Second Surface, Dielectric, Laminate. Thick Film, Composites, Protective Cover Only, Other (Specify)

2 Suggestions for dust contamination rate measurement:

a) $\Delta R / \Delta t$ where $\Delta$ is the change in the reflected (transmitted) power within the solid angle that originally contained $95 \%(2 \sigma)$ of the retilected (transmitted) power at normal incidence.

b) $\Delta \Omega / \Delta t$ where $\Delta \Omega$ is the change in the solid angle containing $95 \%$ of the power reflected (transmitted) at normal incidence. 


\section{ECONOMICS, FUNDAMENTAL LIMITATIONS AND AREAS FOR}

POTENTIAL IMPROVEMENT \begin{tabular}{|l|l|l|l|}
\hline Reflector/Material 1 & $\mathrm{Q}$ & Reflector/Material 2 & $\mathrm{Q}$ \\
\hline
\end{tabular}

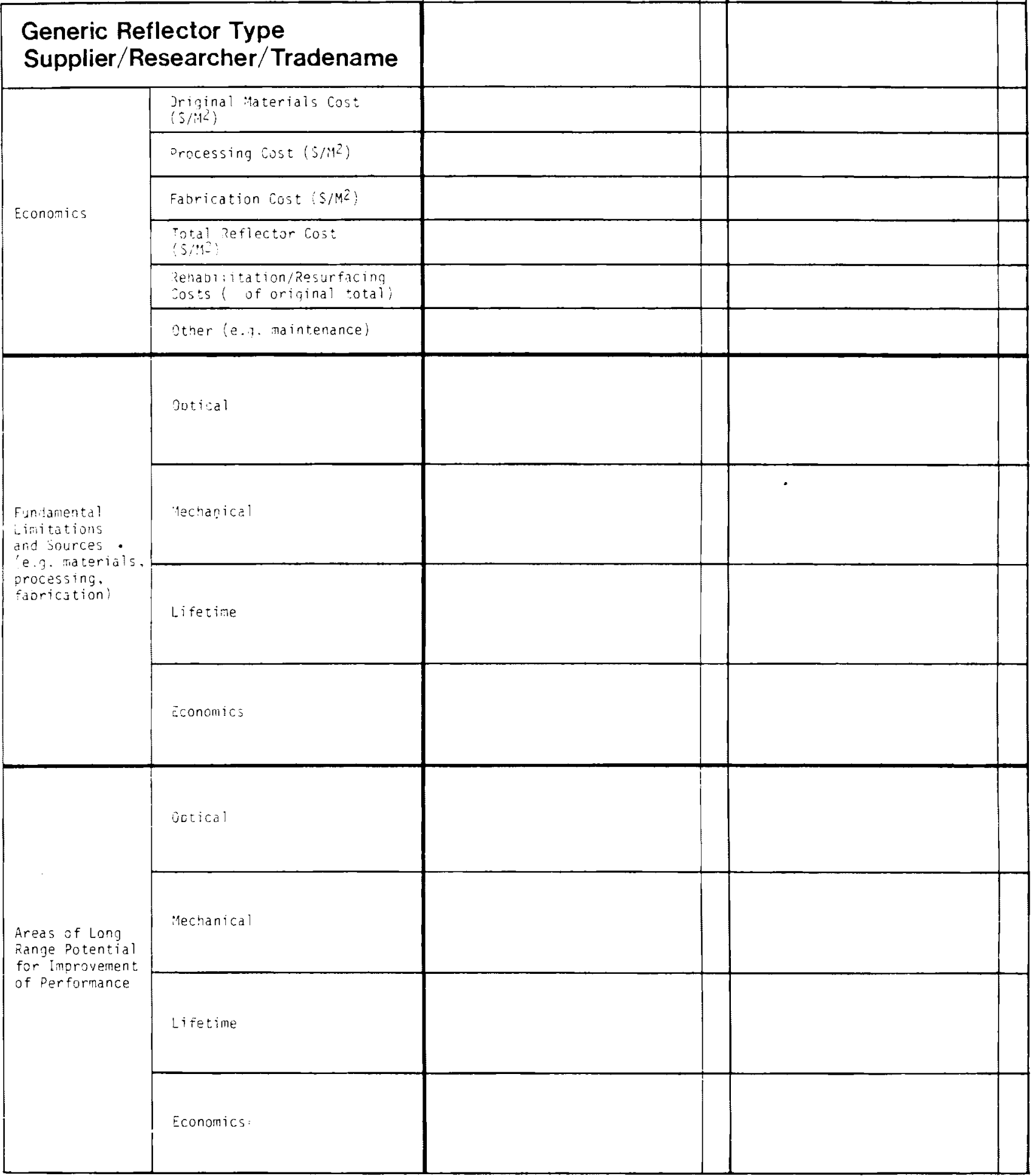




\section{APPENDIX B}

This section of the report contains an alphabetical listing of the registered participants of the Solar Reflective Materials Technology Workshop held at Denver Marina Hotel in Denver, Colorado on March 28-30, 1978. 
P. Bruce Adams

Corning Glass Works

Houghton Park

Corning, NY 14830

607-974-3202

Kamran Aykan

Engelhard Industries

Men lo Park

Edison, NJ 08817

201-321-5292

Rafael Almanza

Instituto de Ingenieria

National University of Mexico

Mexico 20, D.F.

$1-905-548-65-50$

Kirt Bailey

Colorado Technical College

3100 North Wood Avenue

Colorado Springs, CO 80907

George L. Ball III

Monsanto Research Corporation

Box 8, Station B

Dayton, Ohio 45407

513-268-3411

Ed Beauchamp

Sandia Laboratories

Org. 5846

Box 5800

Albuquerque, NM 87115

FTS $-475-8643$

Burton A. Benson

3M Company

3M Center B1dg. 209-2N

St. Paul, MN 55101

612-733-1031

David Benun

Brunswick Corporation

3333 Harbor B 1vd.

Costa Mesa, CA 92629

714-546-8030
Ray Berg

Sand ia Laboratory

Box 5800 Org 5842

Albuquerque, NM 87115

505-264-1668

Marcus Berry

Boeing Engineering \& Construction $8 \mathrm{~K} 70$

P.0. Box 3707

Seattle, WA 98124

$206-773-8624$

Robert M. Bethea

Texas Tech University

Chemical Engineering Department

Lubbock, TX 79409

$806-742-3553$

Joseph Bezborodko

Mechanical Mirror Works, Inc.

661 Edgecomb Avenue

New York, NY 10032

212-795-2100

Floyd Blake

Solar Consultant

7102 S. Franklin St.

Littleton, CO 80122

303-798-0368

Harri Brax

Cryovac

P.0. Box 464

Duncan, SC 29334

803-433-2700

John Brzuskiewicz

IIT Research Institute

10 W. 35th Street

Chicago, IL 60616

$312-567-4369$

*Pat Call

SERI

1536 Cole Blvd.

Golden, CO 80401

303-234-7118 
*William Carroll

Jet Propulsion Laboratory

4800 Oak Grove Drive

Pasadena, CA 91103

Doug Chambers

Advanced Coating Technology

1580 Fishinger Road

Columbus, $\mathrm{OH} 43221$

614-459-3800

Roscoe L. Champion

Sandia Laboratories

Division 5711

Albuquerque, NM 87115

505-264-8643

Thomas R. Coffin

Buchmin Industries

1485 E. Curtiss

Reedley, CA 93711

209-638-3588

Abraham Cohen

Mart in Marietta

Baltimore, MD 21207

301-687-3800

William Coleman

Battelle NW

P.0. Box 999

Richland, WA 99352

509-946-2178

*R. Kirk Collier

Los Alamos Scientif ic Lab

P.0. Box 1663, MS 571

Los Alamos, NM 87545

505-672-224 1

George R. Cunnington

Lockheed Palo Alto Research Lab

3251 Hanover Street

Palo Alto, CA 94304

415-493-4411 ×45136

A1 Czanderna

SERI

1536 Cole Blvd.

Golden, CO 80401

$303-234-7106$
W. Douglas Davis

Thermal Technology Corporation

P.0. Box 130

Snowmass, CO 81654

303-963-3185

William R. Delemeter

Sandia Laboratories

Division 8122

Livermore, CA 94550

415-422-2037

Manuel Delgado

Jacobs-Del Solar Systems Inc.

251 South Lake Avenue

Pasadena, CA 91101

213-264-5900

William E. Dennis

Dow Corning Corporation

M\#500

Box 1592

Midland, MI 48640

John J. Dietrich

McDonne 11 Douglas

5301 Bolsa

Hunt ington Beach, CA 92660

714-896-3066

Robert J. Farrauto

Engelhard Industries

Men lo Park

Edison, NJ 08817

201-654-4376

Rocco J. Fizzano

Martin Processing

P.0. Box 5068

Martinsville, VA 24112

703-629-1711

Bob Frownfelter

PPG Industries Inc.

One Gateway Center

Pittsburgh, PA 15222

412-434-2644 
Melvin W. Frohardt

Martin Marietta

Box 179

Denver, CO 80201

303-973-4988

*Jack E. Gilligan

IITRI

10 W. 35th Street

Chicago, IL 60616

312-567-4325

Pau 1 Gordon

Jet Propulsion Laboratory

4800 Oak Grove Drive

Pasadena, CA 91103

213-577-9421

Richard N. Griffin

General Electric

1 River Road

Schenectady, NY 12345

518-385-9568

Derrick P. Grimmer

Los Alamos Scientific Lab

P.0. Box 1663

Los Alamos, NM 87545

505-667-6441

Bim Gupta

SERI

1536 Cole Blvd.

Golden, CO 80401

303-234-7140

Robert Hahn

Optical Coating Lab

2789 Griff in Avenue

P.0. Box 1599

Santa Rosa, CA 95402

707-545-6440

Buz L. Hampton

Battelle Pacific Northwest Labs

Box 999

Richland, WA 99352

509-946-3687
Brian Howard

Sun-Heet Inc.

2624 South Zuni

Englewood, CO 80110

$303-922-6179$

S. E. Hubbard

Director, Research and Development

Kawneer Company, Inc.

1105 N. Front Street

Niles, MI 49120

616-683-0200

H. Robert Hull

Hexce 1

1171 Dublin Blvd.

Dublin, CA 94566

$415-828-4200$

Jacques L. Hull

ACUREX

385 Clyde Avenue

Mountain View, CA 94042

415-964-3200 ×3366

Robert $W$. Jones

Hughes Aircraft Company

Culver City, CA 90230

213-391-0711

L. J. Kirchner

Glidden-Durkee

3rd \& Bern Streets

Reading, PA 19601

215-373-4111

James A. Knister

Donnelly

49 West 3rd

Holland, MI 49423

616-394-2321

Sam F. Lamensdorf

Binswanger Mirror

Box 17127

Memph is, TN 38117

901-761-3150 
Jim Leonard

Sandia Laboratories

Box 5800

Albuquerque, NM 87115

FTS-475-8508

Mike Lilly

ASG Industries Inc.

Solar Energy Product Department

P.0. Box 929

Kingsport, TN 37662

615-245-2378

*Michae 1 Lind

Battelle Pacific Northwest Labs

P.0. Box 999

Richland, WA 99352

509-946-3676

Matt McCargo

Lockheed Palo Alto Research Labs

Bldg. 205 Dept. 5232

3251 Hannover Street

Palo Alto, CA 94304

415-493-4411 ×45193

William R. McIntire

Argonne National Laboratory

9700 S. Cass Avenue

Argonne, IL 60439

312-972-6246

*C1ayton L. Mavis

Sandia Laboratories

Division 8131

Livermore, CA 94550

415-422-3031

A. Meinel

Optical Sciences Center

University of Arizona

Tucson, AZ 85721

602-884-3138 or 749-3322

Marjorie P. Meine 1

University of Arizona

Tucson, AZ 85721

$602-884-3138$
*Lou Melamed

U.S. Department of Energy

20 Massachusetts Ave., N.W.

Washington, DC 20545

202-376-1938

James A. Menke

Suntec Systems Inc.

21405 Hamburg Avenue

Lakeville, MN 55044

612-469-3471

Roy Miller

American Science \& Engineering

955 Masachusetts Avenue

Cambridge, MA 02139

617-868-1600

William C. Miller

Desert Research Institute

1500 Buchanan

Boulder City, Nevada 89005

702-293-4217

William D. Mitchell

Solaramics

1301 El Segundo Blvd.

E1 Segundo, CA 90245

213-322-9302

Timothy K. Muller

ACUREX

485 Clyde Avenue

Mountain View, CA 94042

415-964-3200

Felipe Monoz

Instituto de Ingenieria

National University of Mexico

Mexico 20, D.F.

$1-905-548-65-50$

R. Mutzberg

PPG Industries

1377 Oakleigh Dr.

East Point, GA 30344

404-761-7771 
Alex Pavlak

P.0. Box 482

Valley Forge, PA 19481

215-783-5855

*Richard Pettit

Sandia Laboratories

Division 5842

Albuquerque, NM 87115

505-264-5678

Charles J. Pignolet

Sandia Laboratories

P.0. Box 969

Livermore, CA 94550

$415-422-2393$

John Powers

ALCOA

ALCOA Technical Center

ALCOA Center, PA 15069

412-339-6651

Roger Rausch

Honeywe 11

2600 Ridgeway Parkway

MN 17-T123

Minneapolis, MN 55413

612-378-5350

Joseph C. Richmond

National Bureau of Standards

Washington, DC 20234

$301-921-2148$

Norman Riise

Del Manufacturing Company

905 Monterey Pass Road

Monterey, CA 91754

213-264-5900

Rodney C. Roberts

3014 South Birch

Denver, CO 80222

303-756-7242

Sus an L. Roche

Sandia Laboratories

Division 8342

Livermore, CA 94550

415-422-2186
Duane F. Rost

General Extrusions, Inc.

General Solar Systems Division

4040 Lake Park Road

Youngstown, $\mathrm{OH} \quad 44514$

216-783-0270

David Rostoker

Pittsburgh Corning Corporation

800 Presque Isle Dr.

Pittsburgh, PA 15239

412-327-6100

John Rusin

Battelle Pacific Northwest Labs

P.0. Box 999

Richland, WA 99352

509-945-2076

Robert J. Sabin

New Mexico State University PSL

Box 3 PSL

Las Cruces, NM 88003

$505-522-4400 \times 209$

William P. Saylor

General Electric Company

P.0. Box 8555

Philadelphia, PA 19101

215-962-5230

George Schrenk

University of Pennsylvania

Department of Mechanical

Engineer ing

111 Twone Building

Philadelphia, PA 19104

FTS-480-5000

Mark Sherwood

Kingston Industries

205 Lexington Avenue

New York, NY 10016

212-889-0196

Arthur Shoemaker

Corning Glass Works

Corning, NY 14830

607-974-7630 
Barry Skolnick

National Metalizing Division

Hanovia Industrial Park

Canburry, NJ 08512

$609-655-4000$

Karl E. Sterne

Direct Energy Corporation

16221 Construction Circle West

Irvine, CA 92714

$714-552-6211$

Milton L. Smith

Texas Tech University

Department of IE

P.0. Box 4130

Lubbock, TX 79407

806-742-3404

Linda M. Sowter

KTA-NPD Energy Systems, Inc.

12300 Washington Avenue

Rockville, MD 20852

301-468-2066

Eric Tornstrom

Mobil Tyco

Solar Energy Division

16 Hickory Drive

Waltham, MA 02154

617-890-0909

John Thornton

Mart in Marietta

P.0. Box 179

Denver, CO 80201

303-973-4978

Donald M. Trotter

L.A.S.S.P.

Cornel1 University

Ithaca, NY 14850

$607-256-3941$

John G. Vega

Martin Marietta

P.0. Box 179, MS 8120

Denver, CO 80201

303-973-3763
Arthur Weinrich

Mirrolab, Inc.

P.0. Box 275

Addison, TX 75001

214-233-3303 (Cal1 Collect)

LeRoy Weinste in

McDonnel1 Douglas

5301 Bolsa Avenue

Huntington Beach, CA 92660

714-896-5098

James E. Windham

Mart in Marietta

103 Chesapeake Park Plaza

Baltimore, MD 21220

301-687-3800 x2239

Frank M. Workens

Falconer Plate Glass Corp.

Falconer, NY 14733

$716-665-6422$

Gene A. Zerlaut

Desert Sunshine Exposure Tests

Box 185 Black Canyon Stage

Phoenix, AZ 85020

$602-465-7521$

* Also served as working group coordinator for workshop session. 
PNL 2763

UC-62

\section{DISTRIBUT ION}

No. of

Copies

OFFSITE

1 DOE Chicago Patent Group 9800 South Cass Avenue Argonne, IL 60439

A. A. Churm

6 DOE-Division of Solar Technology 20 Massachusetts Avenue Washington, DC 20545

G. Braun

M.U. Gutstein

G.M. Kaplan

L. Melamed

J.E. Rannels

J. Weissinger

1 DOE-Office of Solar Application 20 Massachusetts Avenue Washington, DC, 20545

\section{S.L. Sargent}

27 DOE Technical Information Center

95 List of Participants

(See Appendix B)

1 Porter Arbogast North American Sun, Inc. Box 379

Marshalls Creek, PA 18335

1 Calvin C. Beatty Berry Solar Products Woodbridge at Main P 0 Box 327

Edison, NJ 08817
No. of

Copies

OFFSITE

1 Robert A. England

Martin Marietta

MS S0403

P 0 Box 179

Denver, C0 80201

$1 \quad$ I. Earl Lewis

Ford Aerospace \& Communications Corp.

3939 Fabian Way

Palo Alto, CA 94303

1 B. W. Marshall

Sandia Laboratories

Box 5300

Albuquerque, NM 87115

1 Iraida B. Rickling

Florida Solar Energy

Center Library

300 State Road 401

Cape Canaveral, FL 32920

1 A. S. Roy

Oak Ridge National Laboratory 4500-S; B-258

$P 0$ Box $X$

Oak Ridge, TN 37830

$1 \quad$ R. Schultz

Ford Aerospace \& Communi-

cations, Corp.

3939 Fabian Way

MS T-30

Palo Alto, CA 94303

$1 \quad$ Arthur Slemnons

SRI-International 333 Ravenswood Avenue Menlo Park, CA 94025 
PNL 2763

UC-62

\section{DISTRIBUTION}

No. of

Copies

OFFSITE

1 W. M. Smith, Director "A" Absorber Systems 158 W. Broadmoor Blvd. San Leandro, CA 94577

1 W. Toml inson

Environmental Library University of Montana 758 Eddy Street

Missoula, MT 59812

1 Solomon Zwerdling

Northeast Solar Energy Center 70 Memorial Drive

Cambridge, MA 02142
No. of

Copies

ONSITE

1 DOE Richland Operations Office

L. Liffick

57 Pacific Northwest Laboratories

LE Ault

WJ Coleman

K Drumbeller

HL Hampton

JS Hartman

AJ Haverfield

MA Lind (44)

Publishing Coordinator (2)

Technical Information Files (5) 